\title{
Towards regional projections of twenty-first century sea-level change based on IPCC SRES scenarios
}

\author{
A. B. A. Slangen - C. A. Katsman • R. S. W. van de Wal • \\ L. L. A. Vermeersen - R. E. M. Riva
}

Received: 11 October 2010/Accepted: 22 March 2011/Published online: 5 April 2011

(c) The Author(s) 2011. This article is published with open access at Springerlink.com

\begin{abstract}
Sea-level change is often considered to be globally uniform in sea-level projections. However, local relative sea-level (RSL) change can deviate substantially from the global mean. Here, we present maps of twenty-first century local RSL change estimates based on an ensemble of coupled climate model simulations for three emission scenarios. In the Intergovernmental Panel on Climate Change Fourth Assessment Report (IPCC AR4), the same model simulations were used for their projections of global mean sea-level rise. The contribution of the small glaciers and ice caps to local RSL change is calculated with a glacier model, based on a volume-area approach. The contributions of the Greenland and Antarctic ice sheets are obtained from IPCC AR4 estimates. The RSL distribution resulting from the land ice mass changes is then calculated by solving the sea-level equation for a rotating, elastic Earth model. Next, we add the pattern of steric RSL changes obtained from the coupled climate models and a model estimate for the effect of Glacial Isostatic Adjustment. The resulting ensemble mean RSL pattern reveals that many regions will experience RSL changes that differ substantially from the global mean. For
\end{abstract}

\section{A. B. A. Slangen $(\bowtie) \cdot$ R. S. W. van de Wal}

Institute for Marine and Atmospheric research Utrecht, Utrecht University, Princetonplein 5, 3584 CC Utrecht, The Netherlands e-mail: a.slangen@uu.nl

\section{A. Katsman}

Royal Netherlands Meteorological Institute (KNMI), P.O. Box 201, 3730 AE De Bilt, The Netherlands

L. L. A. Vermeersen

Faculty of Aerospace Engineering, TU Delft,

Kluyverweg 1, 2629 HS Delft, The Netherlands

R. E. M. Riva

TU Delft, Kluyverweg 1, 2629 HS Delft, The Netherlands the A1B ensemble, local RSL change values range from -3.91 to $0.79 \mathrm{~m}$, with a global mean of $0.47 \mathrm{~m}$. Although the RSL amplitude differs, the spatial patterns are similar for all three emission scenarios. The spread in the projections is dominated by the distribution of the steric contribution, at least for the processes included in this study. Extreme ice loss scenarios may alter this picture. For individual sites, we find a standard deviation for the combined contributions of approximately $10 \mathrm{~cm}$, regardless of emission scenario.

Keywords Regional sea level - Sea-level projections . Climate change

\section{Introduction}

In a warming climate, the global mean sea level is expected to rise, which will have serious implications for coastal communities (Nicholls and Cazenave 2010). Therefore, sea-level change is a central research topic in climate change studies. The Intergovernmental Panel on Climate Change (IPCC) Fourth Assessment Report (AR4) (Meehl et al. 2007b) presents projections for global sea-level change of $0.21-0.48 \mathrm{~m}$ under the Special Report on Emission Scenarios (SRES) A1B scenario for the period 1980-1999 to 2090-2099, excluding carbon cycle feedbacks and excluding the recently observed dynamical changes in ice sheets. Adding their estimate for the dynamical effect of ice sheet mass loss yields a global estimate of 0.20-0.61 m (Meehl et al. 2007b, Table 10.7).

However, the IPCC projections are limited to a global mean value and do not consider the large regional variations induced by several processes. Possible causes of regional variations include the gravitational effects resulting from land ice mass changes (e.g., Woodward 1887; 
Mitrovica et al. 2001), thermal expansion (e.g., Landerer et al. 2007; Wijffels et al. 2008), ocean dynamics (e.g., Landerer et al. 2007; Yin et al. 2010) and Glacial Isostatic Adjustment (GIA) (e.g., Farrell and Clark 1976; Peltier 2004). In this study we incorporate all these effects in a local scenario using the IPCC SRES scenarios A1B, A2 and $\mathrm{B} 1$, to illustrate the importance of regional sea-level (RSL) variations in a warming climate. Some processes are better understood and modelled in these simulations than others. In particular the ice sheet contributions used in IPCC AR4 were acknowledged to have limitations and possibly underestimate their future contributions (e.g. Rignot et al. 2008a, b, 2011; Velicogna 2009). However, we do apply them here to allow for a comparison of the regional patterns with the well-known global mean IPCC AR4 estimates.

Throughout this paper, all sea-level changes discussed are relative sea-level changes. These are the changes relative to the Earth's surface, as measured by devices attached to the surface, for instance tide gauges. Relative sea-level change is different from absolute sea-level change, which is the change with respect to the center of mass of the Earth, as measured by air-borne devices such as satellite altimeters.

Land ice mass changes represent a large contribution to RSL change. Melt water from land ice does not distribute uniformly over the ocean, due to gravitational effects and induced changes in the shape and rotation of the Earth (e.g., Vermeersen and Sabadini 1999). The gravitational effect is the direct manifestation of Newtons law (mass attracts mass), which implies that land ice attracts ocean water. When ice melts, the gravitational attraction of the ice sheet weakens, so the RSL drops near the ice (up to a radius of $\sim 2,200 \mathrm{~km}$ ), rises less than the global mean from $\sim 2,200$ to $\sim 6,700 \mathrm{~km}$, and rises more than the global mean at a larger radial distance. In addition, changes in surface load (in this case represented by land ice masses and the global ocean) cause a deformation of the Earth's surface, which in turn affects the Earth's gravity field and causes an additional redistribution of ocean water. This coupling between surface mass changes and solid Earth deformation, also known as self-gravitation, was already described by Woodward (1887), but only implemented in a numerical model by Farrell and Clark (1976), who introduced the "Sea-Level Equation". This equation computes both the sea-level change and the solid-Earth deformation due to ice mass variations. In addition, ice melt and solidEarth deformation cause a redistribution of mass that affects the Earth's rotation rate and the position of its rotation axis (e.g., Vermeersen and Sabadini 1999) and hence the RSL change pattern (Milne and Mitrovica 1998).

Another large contribution to RSL change arises from local changes in temperature and salinity of the seawater; the thermosteric and halosteric contributions. Warming of the ocean in response to rising atmospheric temperatures results in an increase of volume and hence sea-level rise. A higher salinity has the opposite effect, as it increases the density of the ocean water. Like the RSL change resulting from land ice mass changes, steric RSL changes (variations in ocean temperature and salinity) are far from spatially uniform (Cazenave and Nerem 2004). Although in many places local thermosteric changes are dominant [see for example Bindoff et al. (2007, Figure 5.15b)], changes in ocean salinity can also lead to substantial local sea-level variations (Antonov et al. 2002). These local steric changes are closely linked to ocean circulation changes, as the latter are driven by local density gradients (Meehl et al. 2007b, Section 10.6.2).

In order to obtain regional patterns of RSL change, the processes mentioned above need to be modelled. The first component considered is the land ice contribution to RSL change. For this contribution, the changes in the ice mass of mountain glaciers and ice caps have been modelled by a volume-area model (Bahr et al. 1997; Van de Wal and Wild 2001), to obtain, in contrast to the IPCC AR4, a regional pattern of the glacier mass loss. Additionally, the mass changes of the Greenland and Antarctic ice sheets have been computed with model-derived relations between temperature and ice sheet mass change as outlined in IPCC AR4 (Meehl et al. 2007b). The magnitude and location of all land ice mass changes serve as input for a sea-level model, which calculates a gravitationally consistent field of RSL change while accounting for rotational processes. The second component considered is the steric component (i.e. changes in ocean density and circulation), for which we use the results of Atmosphere-Ocean coupled General Circulation Models (AOGCM's) provided in the Coupled Model Intercomparison Project phase 3 (CMIP3) database (Meehl et al. 2007a). The AOGCM's provide a global mean and local sea-level change relative to the mean due to circulation changes resulting from temperature and salinity variations. The third component added is the sea-level change resulting from GIA, which is the present-day viscoelastic response of the Earth's crust to changes in ice masses throughout the last glacial cycle. To model the influence of GIA on regional sea-level change the result of the ICE-5G(VM2) glaciationdeglaciation model (Peltier 2004) is used.

To allow for a comparison of the IPCC AR4 global mean estimates (Meehl et al. 2007b) to the regional patterns, all results presented in this study are, on purpose, based on the same data as used in IPCC AR4. The only exception is the use of a new data set for the contribution of mountain glaciers and ice caps. The reason for this is that the present study requires a data set that provides locations and initial volume of the individual glaciers to calculate regional scenarios for this contribution, while the IPCC 
data only provide a global value for all mountain glaciers and ice caps combined. The outcome of this study is to be considered as a first step towards the development of regional projections for sea-level change, complementary to the global mean projections in IPCC AR4. Although in IPCC AR4 the self-gravitation effect is recognized as a cause of regional RSL variations (Bindoff et al. 2007, Section 5.5.4.4), it is not considered for the projections of future sea-level change (Meehl et al. 2007b). Here we will quantify this effect in detail. The local variations in steric sea-level change were discussed in Meehl et al. (2007b). Additionally to the contributions presented in IPCC AR4, the influence of GIA on sea-level change is considered, which can have very large effects locally.

This study is the first attempt to combine the three most important components affecting sea-level change on a regional scale, which has not been done before to our knowledge. Scientifically all ingredients are available for these three components to make the step from global projections to local projections and to provide specialized information regarding RSL change, for which there is an increasing demand from governments and policy makers.

There are some potential contributions to local RSL variations that are not included in this study because of a lack of appropriate data or model results. Examples are surface movements due to tectonic effects or subsidence, changes in storm surge height (although climatic changes of wind direction and wind speed are included in the steric contribution), water impoundment behind dams, groundwater storage change and the influence of freshening due to land ice melt on the ocean circulation. Hence, the results of this study should be considered as a first attempt to construct a regional projection for RSL change with room for improvement as science progresses.

The paper is structured as follows. Section 2 describes all models and the data used to construct the spatially varying fields of RSL change. In Sect. 3 the results are shown, for the separate contributions and for the total projected RSL change. A discussion of the results is presented in Sect. 4 and finally in Sect. 5 the conclusions are described.

\section{Data and methodology}

In this section, all models and data used in this study are discussed. A schematic of the methodology applied to construct the scenarios for local RSL change is presented in Fig. 1. The land ice contribution is split up in two components: the small mountain glaciers and ice caps (Sect. 2.1.1), and the large ice sheets, Greenland and Antarctica (Sect. 2.1.2). Both respond differently to climatic changes and thus the ice mass changes need to be modelled in a different way. Once the magnitude and locations of all land ice mass changes are known, a sealevel model is used to compute the local RSL pattern resulting from the melting land ice. This is described in Sect. 2.1.3. The spatial pattern of the steric contribution is computed using global mean thermal expansion data and local RSL anomalies due to temperature and salinity variations (Sect. 2.2). To account for the present-day response to ice mass changes after the Last Glacial Maximum, a spatially varying field of GIA is taken from the ICE-5G(VM2) model (Sect. 2.3), and added to the other contributions. This results in spatial patterns of future RSL change, which will be discussed in Sect. 3. This section ends with a description of the coupled climate models that provide most of the data used to calculate both the land ice and the steric contributions (Sect. 2.4).

\subsection{Land ice contribution}

\subsubsection{Mountain glaciers and ice caps}

We use a glacier model to estimate the RSL change contribution from mass changes of mountain glaciers and ice caps (henceforth glaciers), which is defined as all land ice apart from the Antarctic ice sheet and the Greenland ice sheet. This model is based on volume-area scaling (e.g., Bahr et al. 1997; Van de Wal and Wild 2001; Radić et al. 2007, 2008). It computes the volume change of all glaciers, sorted by region and surface area, while accounting for the change of glacier area in time, temperature changes and precipitation changes, by using the mass balance sensitivity:

$$
\begin{aligned}
& \frac{d V}{d t}=\sum_{j=1}^{n} \sum_{k=1}^{m} A(j, k, t) \times\left\{\Delta T_{s}(j, t) \frac{d B_{P(j, t)}}{d T_{s}}\right. \\
& \left.+\Delta T_{n s}(j, t) \frac{d B_{P(j, t)}}{d T_{n s}}+\Delta P(j, t)\right\}
\end{aligned}
$$

In Eq. 1, glacier area $A$ is summed over $n$ regions and $m$ size bins (discussed below). The mass balance sensitivity $d B_{P(j, t)}$ is a function of the local precipitation $P$ using values from Zuo and Oerlemans (1997), but also results from changes in local summer temperature change $\left(\Delta T_{s}\right)$ (summer is JJA in northern hemisphere, DJF in southern hemisphere) as well as non-summer temperature change $\left(\Delta T_{n s}\right) . T$ and $P$ are taken from the AOGCM's (Sect. 2.4) using the nearest neighbour approach (Van de Wal and Wild 2001). The imbalance of glaciers at present is accounted for by starting the calculations in 1865, and applying a temperature increase of $0.6^{\circ} \mathrm{C} / 100$ years over the period 1865-1990.

The relation between volume $V$ and area $A$ for a glacier is assumed to follow a power law (Bahr et al. 1997): 
Fig. 1 Schematic depicting the methodology applied in this study. Global climate models provide temperature $(\mathrm{T})$ and precipitation $(\mathrm{P})$ required to calculate the land ice contributions, and global mean thermal expansion and local sea-level anomalies due to temperature and salinity variations for the steric brackets refer to the subsections in which the different components are discussed contribution. Numbers in

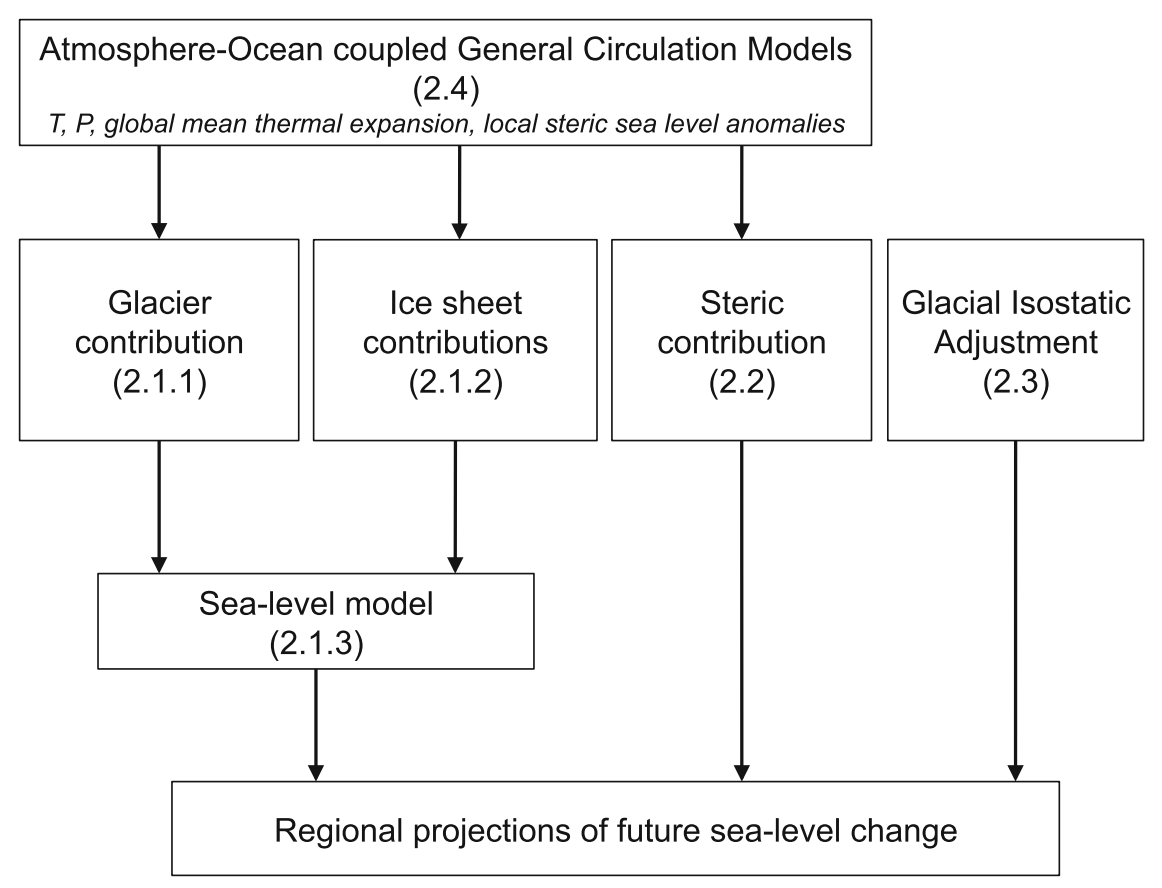

$V=c A^{\gamma}$,

glaciers. These different data sets result in different values for the glacier contribution; for the A1B scenario this study uses $0.13-0.25 \mathrm{~m}$ SLE, while in IPCC AR4 this is 0.08$0.15 \mathrm{~m}$ SLE (5-95\% range).

The Radić and Hock data consist primarily of the WGIXF database (Cogley 2009), which contains information on more than 131,000 glaciers and about half of the estimated area of the world's glaciers. Radić and Hock added 16 Icelandic ice caps and 47 Alaskan mountain glaciers to the Cogley data set. All available glaciers are sorted into $n=19$ regions (Radić and Hock 2010, their Figure 1) and $m=18$ size bins with upper area size $2^{l} \mathrm{~km}^{2}, l=-3$ to 14. In addition, upscaling is performed for 10 of the 19 regions for which the inventory was not complete, where all upscaled area is assumed to be glaciers, not ice caps. Regions, size bins and upscaling are according to Radić and Hock (2010). The upscaled glacier data set finally serves as input data for the glacier model. The glacier model then computes glacier mass changes for the period 1980-1999 to 2090-2099, based on the IPCC scenarios. Eventually these volume changes are used as input for the sea-level model (described in Sect. 2.1.3).

\subsubsection{Antarctic and Greenland ice sheet}

The two largest ice masses on Earth are the Greenland Ice Sheet (GIS) and the Antarctic Ice Sheet (AIS). To model their contribution to RSL change due to future ice mass changes, we need a different approach from the glaciers described in the previous section. The volume-area approach is not suitable for ice sheets, due to their different size, geometry and 
dominating physical processes. Instead, in IPCC AR4 (Meehl et al. 2007b, Section 10.6.4) the mass changes of the ice sheets are divided into three parts to calculate the contributions of AIS and GIS: surface mass balance (SMB) changes (accumulation and ablation), a dynamical contribution (changes in ice flow and reaction to changes in topography) and scaled-up ice sheet discharge (estimation for the imbalance due to observed ice flow acceleration). Here, we briefly explain the procedures followed to calculate each of the three parts, which are identical to those applied in IPCC AR4, except for the separation of GIS and AIS contributions to be able to account for the gravitational effect. Additionally, Table 1 clarifies the followed procedure.

To determine future SMB changes, Gregory and Huybrechts (2006) combined annual time-series of temperature and precipitation simulated by low resolution AOGCM's, with spatial and seasonal patterns simulated by 4 high-resolution Atmosphere General Circulation Models (AGCM). This results in empirical relations of the form

$\frac{\Delta S M B}{\Delta t}=a+b \Delta T_{1}+c \Delta T_{1}^{2}$

describing the relation between the SMB contribution of GIS and AIS to RSL change $\left(\frac{\Delta S M B}{\Delta t}\right.$, in $\mathrm{mm} /$ year) and the global temperature change with respect to pre-industrial values $\left(\Delta T_{1}\right) . a, b$ and $c$ are ice sheet-, model- and scenario-specific constants (Gregory and Huybrechts 2006, J. Gregory, personal communication, 2010). Equation 3 is solved for all combinations of the 4 high-resolution AGCM's and the total ensemble of AOGCM's used in this study (12, 11 and 10 for respectively $\mathrm{A} 1 \mathrm{~B}, \mathrm{~B} 1$ and $\mathrm{A} 2$ ), and for the two ice sheets separately, resulting in 264 equations with different constants $a, b$ and $c$. Finally, the SMB contributions of GIS and AIS for each AOGCM are calculated using the average $\triangle S M B$ of the 4 high-resolution GCM's.

The dynamical contribution is calculated by scaling the SMB values and adding an estimate for the ice sheet contributions to RSL change in 1993-2003. The scaling factors used in IPCC AR4 are $-5 \% \pm 5 \%$ for AIS and

Table 1 Empirical relations used to estimate the contributions of future ice mass changes of the Greenland and Antarctic ice sheets

\begin{tabular}{lll}
\hline Ice sheet & GIS & AIS \\
\hline SMB & $a+b \Delta T_{1}+c \Delta T_{1}^{2}$ & $a+b \Delta T_{1}+c \Delta T_{1}^{2}$ \\
Dynamical & $S M B+\frac{1}{3} * r_{1}$ & $S M B * 0.95+\frac{2}{3} * r_{1}$ \\
Scaled-up & $\frac{1}{3} * r_{1}\left(\Delta T_{2} / 0.63\right)$ & $\frac{2}{3} * r_{1}\left(\Delta T_{2} / 0.63\right)$ \\
\hline
\end{tabular}

Constants $a, b$ and $c$ are dependent on ice sheet, AOGCM and scenario (J. Gregory, personal communication). $\Delta T_{1}$ is the global mean difference between $T_{t \text { (2001-2099) }}-T_{\text {ave (1865-1894). }} \Delta T_{2}$ is the global mean difference between $T_{t \text { (2001-2099) }}-T_{\text {ave }}(1980-1999) \cdot r_{1}=0.32$ $\mathrm{mm} /$ year (Meehl et al. 2007b)
$0 \% \pm 10 \%$ for GIS. Additionally the central estimate for the 1993-2003 sea-level contribution of AIS plus half that of GIS is used as scenario-independent term $r_{1}$ $\left(r_{1}=0.32 \mathrm{~mm} /\right.$ year, Meehl et al. 2007b, Section 10.6.5). We need to split up the GIS and AIS contributions, because the influence on local RSL change is dependent on the location where the land ice mass changes take place. Therefore, we assign $\frac{2}{3}$ of $r_{1}$ to AIS and $\frac{1}{3}$ of $r_{1}$ to GIS, similar to the way Meehl et al. (2007b) constructed $r_{1}$.

To estimate the present-day ice sheet imbalance, it is assumed that the imbalance scales with the global average temperature change (Meehl et al. 2007b, Sections 10.6.5 and 10.A.5). For the calculation of the scaled-up ice sheet discharge we first assign the same fractions to $r_{1}$ as for the dynamical changes. Next, $r_{1}$ is multiplied with the future temperature change relative to that over 1980-1999 $\left(\Delta T_{2}\right)$ and divided by the global average temperature difference between 1865-1894 (pre-industrial) and 1993-2003 $\left(0.63^{\circ} \mathrm{C}\right.$, Meehl et al. 2007b, Section 10.A.5).

The ice sheet mass changes need to be assigned to a location to enable the calculation of a spatial pattern of RSL change by the sea-level model (Sect. 2.1.3). For AIS, all mass change is assumed to take place on the Antarctic Peninsula and in West Antarctica (e.g. Rignot et al. 2008a), while for GIS the west coast and south part of Greenland are the assigned melt areas (e.g., Ettema et al. 2009; Rignot et al. 2008b). The mass change is distributed evenly over the area indicated with white shading in Fig. 2, upper left panel. Distributing the mass evenly is a simplification that will probably influence the resulting pattern in RSL change (Gomez et al. 2010). This is a refinement that needs to be addressed in future work to improve the accuracy of the estimates, if more subtle processes are included. However, in this study it was not taken into account.

\subsubsection{Sea-level model}

The sea-level model applied in this study (Schotman 2008) solves the sea-level equation using a pseudo-spectral approach (Mitrovica and Peltier 1991), and includes the influence of changes in the Earth's rotation (Milne and Mitrovica 1998). The Earth model is based on PREM (Dziewonski and Anderson 1981), and is elastic, compressible and radially stratified. Results are computed on a grid of 512 longitude and 256 latitude points. The input information on the location and magnitude of land ice changes is obtained from Sects. 2.1.1 and 2.1.2. The ice density is fixed at $918 \mathrm{~kg} / \mathrm{m}^{3}$ and the ocean density at $1,028 \mathrm{~kg} / \mathrm{m}^{3}$ (Millard et al. 1987). This sea-level model considers only the short-term response of the Earth and oceans to changes in present-day ice masses. The long-term response to melt after the Last Glacial Maximum is considered separately in Sect. 2.3. 

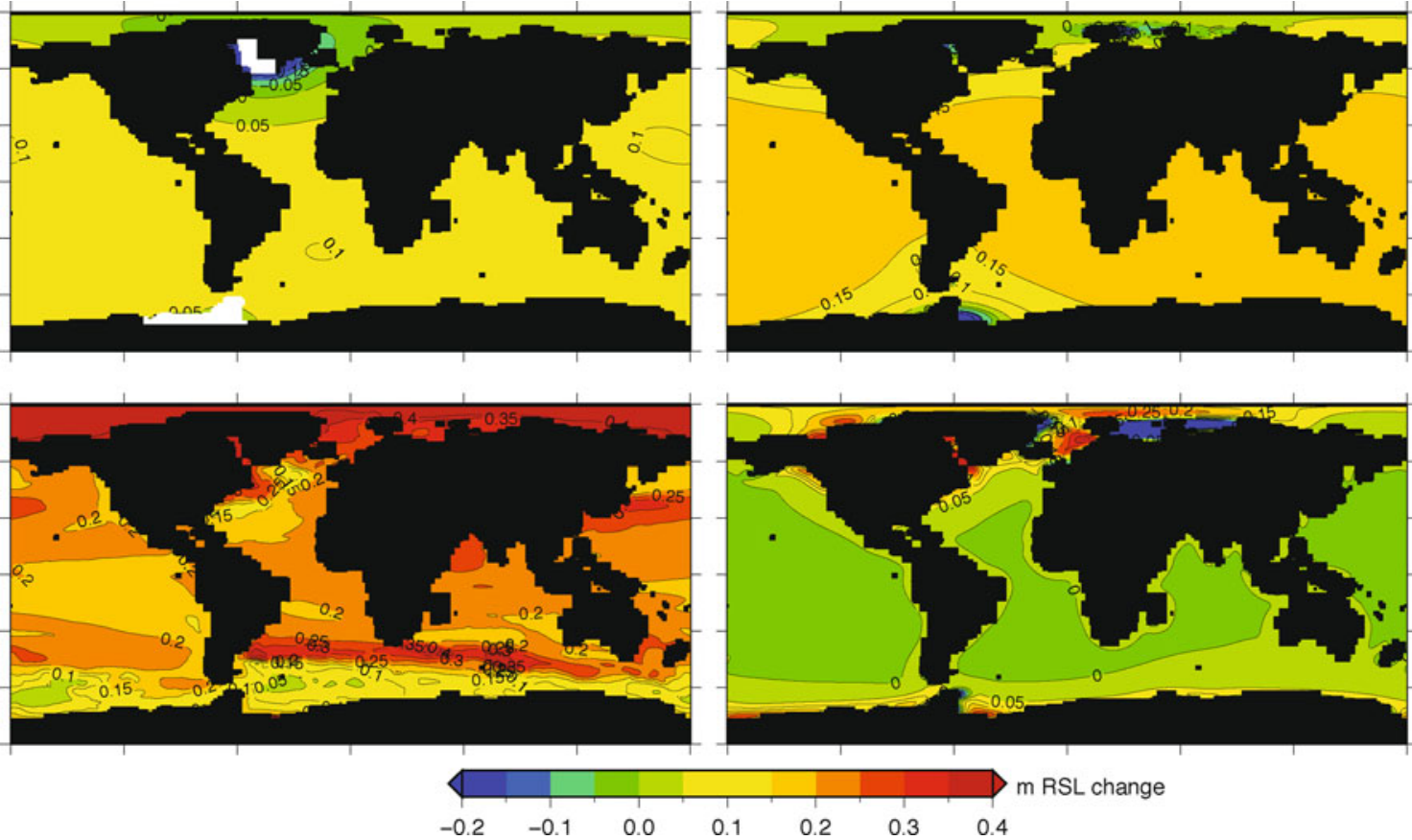

Fig. 2 Ensemble mean RSL contribution ( $\mathrm{m}$ ) of ice sheets (upper left), glaciers (upper right), steric changes (lower left) and GIA (lower right) for scenario A1B between 1980-1999 and 2090-2099. White shading in upper left panel indicates the mass loss regions on AIS and GIS

\subsection{Steric contribution}

Global mean steric RSL changes are dominated by the thermosteric part (e.g., Cazenave et al. 2009; Willis et al. 2008), since the global mean ocean salinity hardly changes over time. Therefore, it suffices to only take into account the global mean thermal expansion projected by the AOGCM's over the considered time period when calculating the steric part of the local RSL projection. Time series of global mean thermal expansion were obtained from the CMIP3 database (Meehl et al. 2007a) and have been presented in IPCC AR4 (Figure 10.31). They were corrected for model drift by subtracting the nearly linear trend found in the accompanying preindustrial control run.

To this global mean component, we add the local RSL anomalies projected by the AOGCM's associated with circulation changes due to temperature and salinity variations [which are also available from the CMIP3 database, Meehl et al. (2007a)]. By construction, the global mean of the sealevel anomaly field is zero. These local RSL anomalies display large natural variability on interdecadal timescales. To filter out these slow variations, we first calculate the linear regression of local sea level over the twenty-first century at each grid point before calculating the local RSL anomalies.

\subsection{Glacial isostatic adjustment (GIA)}

During the last glacial maximum, some 20,000 years ago, large parts of the Northern hemisphere were covered by ice. The loading of the ice caused a redistribution of internal mass and deformation of the Earth's surface. When the ice started melting, the Earth did not immediately return to its original shape, because of the delayed response of the viscoelastic mantle. In fact, the Earth is still adjusting today, with maximum uplift rates of around $1 \mathrm{~cm}$ per year to be found in the Gulf of Bothnia and Hudson bay (e.g. Vermeersen and Sabadini 1999). In contrast to the influence of present-day melt of glaciers and ice sheets on RSL change (described in Sect. 2.1), which can be computed by modelling the elastic response of the Earth, the melt of Pleistocene ice sheets has to be computed by modelling its viscoelastic response. GIA models are models of the whole glacial cycle, mainly constrained by sealevel information found in for instance corals and sediment cores. Unless mentioned otherwise, we use the present-day GIA resulting from ICE-5G(VM2) (Peltier 2004). In Sect. 4.1 we will use the ANU model (Nakada and Lambeck 1988, updated in 2004-2005), to illustrate the sensitivity of our results to the choice of GIA model. For the time scale of this study, the RSL changes due to GIA are almost constant; therefore, they are applied as a stationary spatial pattern.

\subsection{Model ensemble}

The RSL estimates described in this paper are calculated using the results of simulations with the AOGCM's given in Table 2. These models are a subset of the World Climate 
Table 2 CMIP3-models used in this study

\begin{tabular}{ll}
\hline AOGCM & Reference \\
\hline BCCR-BCM2.0 & Furevik et al. (2003) \\
CGCM3.1(T47) & Flato (2005) \\
ECHAM5/MPI-OM & Jungclaus et al. (2006) \\
GFDL-CM2.0 & Delworth et al. (2006) \\
GFDL-CM2.1 & Delworth et al. (2006) \\
GISS-EH* & Schmidt et al. (2006) \\
GISS-ER & Schmidt et al. (2006) \\
GISS-AOM & Lucarini and Russell (2002) \\
MRI-CGCM2.3.2 & Yukimoto and Noda (2002) \\
MIROC3.2(hires) & K-1 Model Developers (2004) \\
NCAR-PCM & Washington et al. (2000) \\
UKMO-HadCM3 & Gordon et al. (2000) \\
\hline
\end{tabular}

* Not available for A2 and B1

+ Not available for A2

Research Programme's CMIP3 multi-model dataset (Meehl et al. 2007a) used for IPCC AR4. This subset contains all models for which all required variables were available. For the selected models we consider three different emission scenarios: B1, A1B and A2, which are defined in the IPCC Special Report on Emission Scenarios (Nakicenovic and Swart 2000). The ensemble mean global average temperature increase in $2090-2099$ w.r.t. $1980-1999$ is $+1.8^{\circ} \mathrm{C}$ $\left(1.1-2.9^{\circ} \mathrm{C}\right)$ for $\mathrm{B} 1,+2.8^{\circ} \mathrm{C}\left(1.7-4.4^{\circ} \mathrm{C}\right)$ for $\mathrm{A} 1 \mathrm{~B}$, and $+3.4^{\circ} \mathrm{C}\left(2.0-5.4^{\circ} \mathrm{C}\right.$ ) for $\mathrm{A} 2$ (Meehl et al. 2007b).

The period over which we consider local RSL change is the same as in IPCC AR4 (Table 10.7): the difference between 1980-1999 and 2090-2099. For this period, we extract atmospheric temperature, precipitation, the global mean thermal expansion and the local RSL anomalies due to temperature and salinity changes from the model database (Meehl et al. 2007a). For the ice sheets (Sect. 2.1.2) we need additional information on the global average temperature of the pre-industrial climate (defined as the period 1865-1894), taken from the twentieth century reference runs.

As the resolution of the different models is highly variable, the data need to be interpolated to one grid to be able to construct an ensemble mean. We choose a grid with 512 longitude points and 256 latitude points, as this is the output grid of the sea-level model used to model RSL change resulting from the land ice contributions (Sect. 2.1.3).

The size of the surface area of the ocean is model dependent. However, if a grid point is assigned to land in one model and to ocean in another, this complicates comparisons between models, and especially the calculation of an ensemble mean. Therefore, in this study, RSL change for the ensemble mean is calculated using a universal land-ocean mask which contains ocean surface area only at those grid points where all the models have ocean points. Use of the universal mask reduces the total ocean surface area with respect to the model-specific masks, leading to minor deviations in total RSL change in the order of $2 \%$.

\section{Projections of local RSL change}

\subsection{Global mean projections}

In Table 3 the global mean values calculated in this study are compared to the results presented in Meehl et al. (2007b, Table 10.7), for the emission scenario A1B. The table shows that the results in this study are in line with IPCC AR4, but also that there are a few differences. Firstly, a different ensemble of AOGCM's is used for the calculations, which influences the spread in the results of all contributions, except GIA. Secondly, a different glacier data set was used because locations of land ice melt were needed to calculate the regional glacier contribution. Also, GIA was added in this study, which is a small effect globally averaged, but can be large locally. The last difference is that the scaled-up ice sheet discharge is separated for the two ice sheets in this study.

Table 4 lists the global mean values for the three emission scenarios of all the modelled RSL contributions and the resulting total RSL change, obtained using the methodology described in Sect. 2. The uncertainties presented in the table represent one standard deviation within the model ensemble. Not surprisingly, the scenario with the lowest greenhouse gas emissions, B1 (11-model ensemble), predicts the lowest RSL rise, while the high emission A2 scenario (10-model ensemble) yields the highest estimates. Table 4 shows that the global average GIA is slightly positive, but very small. As GIA is a long-term effect, it is not influenced by present-day changes, and is therefore the same for all scenarios. The glaciers contribute a global mean volume change of $0.17 \pm 0.04 \mathrm{~m}$ SLE for A1B, which is the dominant part of the land ice contribution. Using the IPCC AR4 approach, we find that the ice sheets (now including the estimate for the scaled-up ice sheet discharge) contribute $0.01 \pm 0.02 \mathrm{~m}$ from Antarctica and $0.08 \pm 0.02 \mathrm{~m}$ from Greenland. The low value of Antarctica follows from a near cancellation between the negative SMB contribution and the positive value for the scaled-up ice sheet discharge. Recent literature (e.g. Rignot et al. 2008a, b, 2011; Velicogna 2009) challenges these estimates, as current observations of the mass loss on the ice sheets indicate that this contribution might be larger. 
Table 3 Projected global average of RSL change (m) for SRES scenario A1B between 1980-1999 and 2090-2099, comparing this study to IPCC AR4 estimates (their Table 10.7)

\begin{tabular}{lcll}
\hline & This study & IPCC AR4 & Remarks \\
\hline Steric & $0.14-0.30$ & $0.13-0.32$ & Different model ensemble (this study 12, IPCC AR4 16) \\
Glaciers & $0.13-0.25$ & $0.08-0.15$ & Regionally distributed data set in this study \\
AIS & $-0.08--0.01$ & $-0.12--0.02$ & \\
GIS & $0.04-0.08$ & $0.01-0.08$ & Not computed in IPCC AR4 \\
GIA & $-0.001-0.009$ & - & \\
Sum & $0.30-0.55$ & $0.21-0.48$ & AIS and GIS combined in IPCC AR4: $-0.01-0.13$ \\
Scaled-up AIS & $0.04-0.06$ & - & \\
Scaled-up GIS & $0.02-0.03$ & - & \\
\hline
\end{tabular}

The range given is $5-95 \%$

Table 4 Projected ensemble mean global average of RSL change (m) for SRES scenarios B1 (low), A1B (middle) and A2 (high) between 1980-1999 and 2090-2099

\begin{tabular}{llll}
\hline & B1 & A1B & A2 \\
\hline Steric & $0.16 \pm 0.08$ & $0.21 \pm 0.09$ & $0.27 \pm 0.17$ \\
Glaciers & $0.14 \pm 0.03$ & $0.17 \pm 0.04$ & $0.19 \pm 0.04$ \\
AIS & $0.01 \pm 0.02$ & $0.01 \pm 0.02$ & $0.01 \pm 0.03$ \\
GIS & $0.06 \pm 0.01$ & $0.08 \pm 0.02$ & $0.08 \pm 0.02$ \\
GIA & $0.004 \pm 0.003$ & $0.004 \pm 0.003$ & $0.004 \pm 0.003$ \\
Sum & $0.37 \pm 0.09$ & $0.47 \pm 0.11$ & $0.55 \pm 0.17$ \\
\hline
\end{tabular}

The sum includes the steric contribution, all land ice (including scaled-up ice sheet discharge) and GIA. Contrarily to Table 3, the uncertainties here are $1 \sigma$ between 11 models (B1), 12 models (A1B) and 10 models (A2)

We will elaborate on this topic in the discussion section (Sect. 4.1), where the influence of a larger ice sheet contribution is demonstrated. However, here we will continue to use the IPCC AR4 ice sheet estimates, including the scaled-up ice sheet discharge, to allow for a comparison of the regional patterns to the IPCC AR4 global mean values.

Although significantly less ice is stored in glaciers than in the GIS and the AIS, glacier melt still provides a relatively large contribution to RSL change. This is caused by the higher sensitivity of glaciers to climate change due to their larger mass turnover. The steric contribution has values similar to the total land ice contribution, so each accounts for about $50 \%$ of the global mean RSL change. This implies that the total spatial pattern will depend on the steric as well as the land ice contribution, as will be shown in Sect. 3.3.

\subsection{Spatial patterns of the different contributions}

The regional patterns of the separate contributions for scenario A1B are shown in Fig. 2. We focus on this emission scenario from now on, because it has the largest available ensemble. Between the scenarios the amplitudes change, but the patterns are very similar.
The upper left panel of Fig. 2 shows the RSL change resulting from mass changes of the ice sheets. Because the AIS contribution based on the IPCC AR4 estimates is very small (Table 4), the pattern shown in Fig. 2 mainly results from mass changes of the GIS. The signature of the selfgravitation effect is clearly visible: an RSL drop close to the largest melt source (GIS) and an above average RSL rise in the Southern Hemisphere. In the upper right panel, representing the contribution of the glaciers, the selfgravitation effect is also clearly visible, but now for multiple melt sources. As most ice melts in the Northern Hemisphere, RSL will rise by at least the global mean value south of the equator, with the exception of the RSL close to the Antarctic Peninsula and the Patagonian ice fields, where values are lower due to local ice mass loss. The contributions of ice sheets and glaciers combined lead to a large range for the local RSL change of -3.96 to $0.30 \mathrm{~m}$, with a global mean of $0.26 \mathrm{~m}$.

The lower left panel of Fig. 2 shows the steric contribution. The pattern displays a large spatial variability. For example, the region around Antarctica will experience less sea-level change than the global mean, while according to the climate models sea-level change in the Arctic Ocean will be larger than average. The steric changes range from 0.01 to $0.48 \mathrm{~m}$, with a global mean of $0.21 \mathrm{~m}$. The pattern closely resembles that shown in Figure 10.32 of Meehl et al. (2007b) (note that in the latter the local sea-level change relative to the global mean is shown while here the global mean is included). This indicates that despite our smaller model ensemble (12 AOGCMs versus 16 AOGCMs in AR4), we do capture the general features of the steric pattern. The underlying causes for these spatial variations in steric sea-level change were discussed in Meehl et al. (2007b, Section 10.6.2). For example, the relatively large steric change in the Arctic Ocean is attributed to ocean freshening, while the minimum found in the Southern Ocean is due to changes in wind stress (Landerer et al. 2007) or small thermal expansion (Lowe and Gregory 2006). 

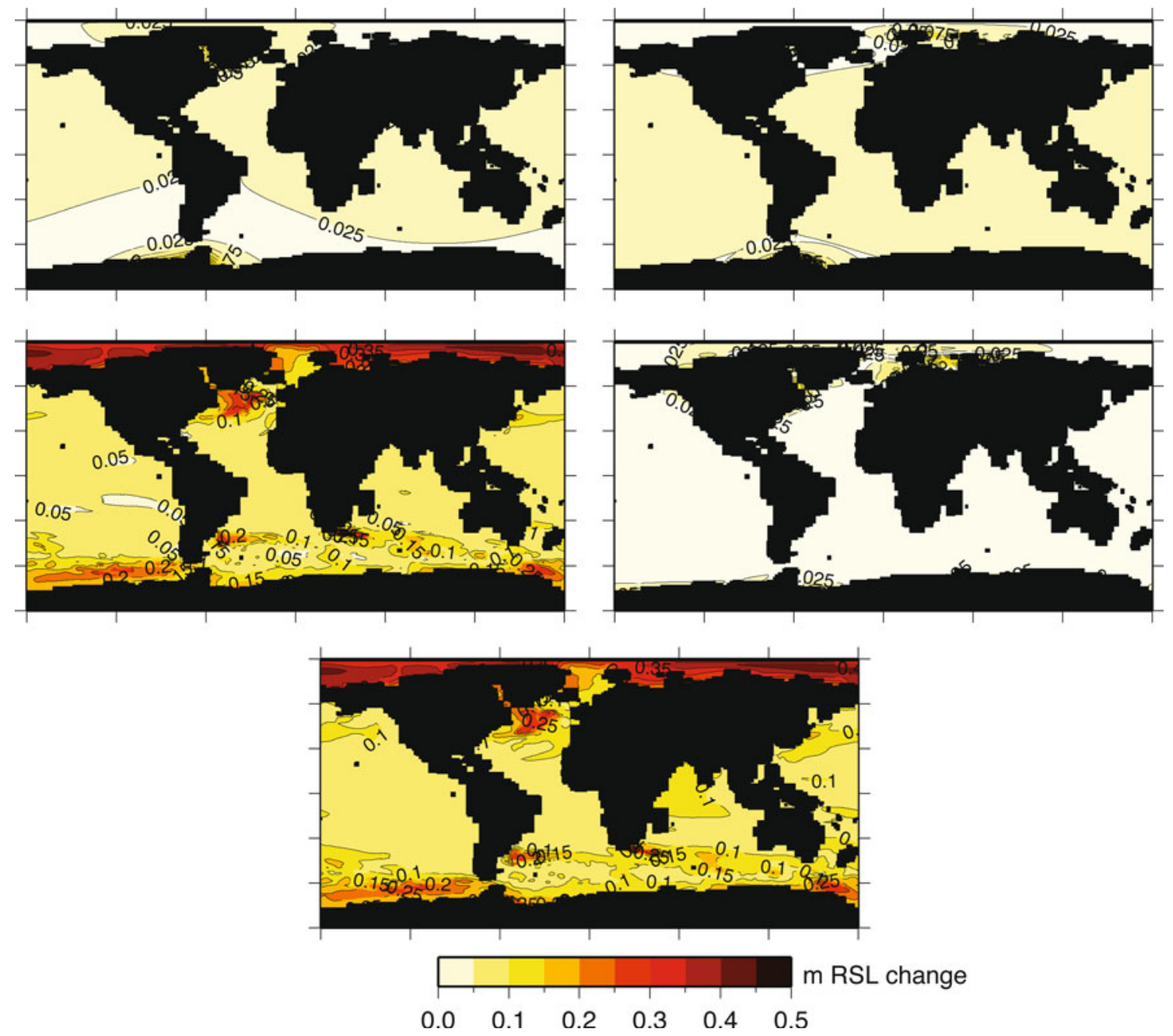

Fig. 3 Ensemble local standard deviation ( $\mathrm{m}$ ) of the RSL contribution of ice sheets (upper left), glaciers (upper right), steric changes (middle left), GIA (middle right) and all four contributions combined (lower centre) for scenario A1B between 1980-1999 and 2090-2099

As GIA (Fig. 2, lower right panel) is resulting from melt of the Laurentide and Fennoscandian ice sheets, the largest rates of crustal deformation due to GIA can be found in North America and Scandinavia. Changes are largest over land, but also the sea level is influenced: RSL change values range from -0.73 to $0.59 \mathrm{~m}$, with a global mean of $0.004 \mathrm{~m}$. While on average GIA is a small effect, in and near the regions previously covered by land ice the effect can still be quite large, and sometimes even dominate the other contributions (e.g. Scandinavia).

The standard deviations of the different contributions to RSL change for the A1B ensemble are shown in Fig. 3. The upper left panel shows the standard deviation of the ice sheet contribution, while the upper right depicts the glacier standard deviations. In both panels we find the largest uncertainties close to locations with large ice mass changes: Antarctica, Greenland and the larger glacier areas, e.g. Svalbard. As this is where the gradients due to the selfgravitation effect are the largest, a small change in mass change will result in relatively large changes in the gradients. The middle left panel represents the $\sigma$ of the steric contribution, with significantly higher values than for the land ice contributions. The largest standard deviations can be found in the Arctic Ocean, because the models disagree on the effects of Arctic freshening. To GIA we assign an average uncertainty of $20 \%$ (middle right panel), which is based on the difference between the ICE-5G(VM2)-model (Peltier 2004) and the ANU-model (Nakada and Lambeck 1988, updated in 2004-2005). As the GIA signal is generally quite small, this mainly results in small uncertainties. The lower panel represents the total ensemble mean standard deviation and will be discussed in Sect. 3.3.

\subsection{Total projections of local RSL change}

In this section we consider the total projections for local RSL change using the contributions calculated in the previous section. All land ice, steric and GIA contributions are 

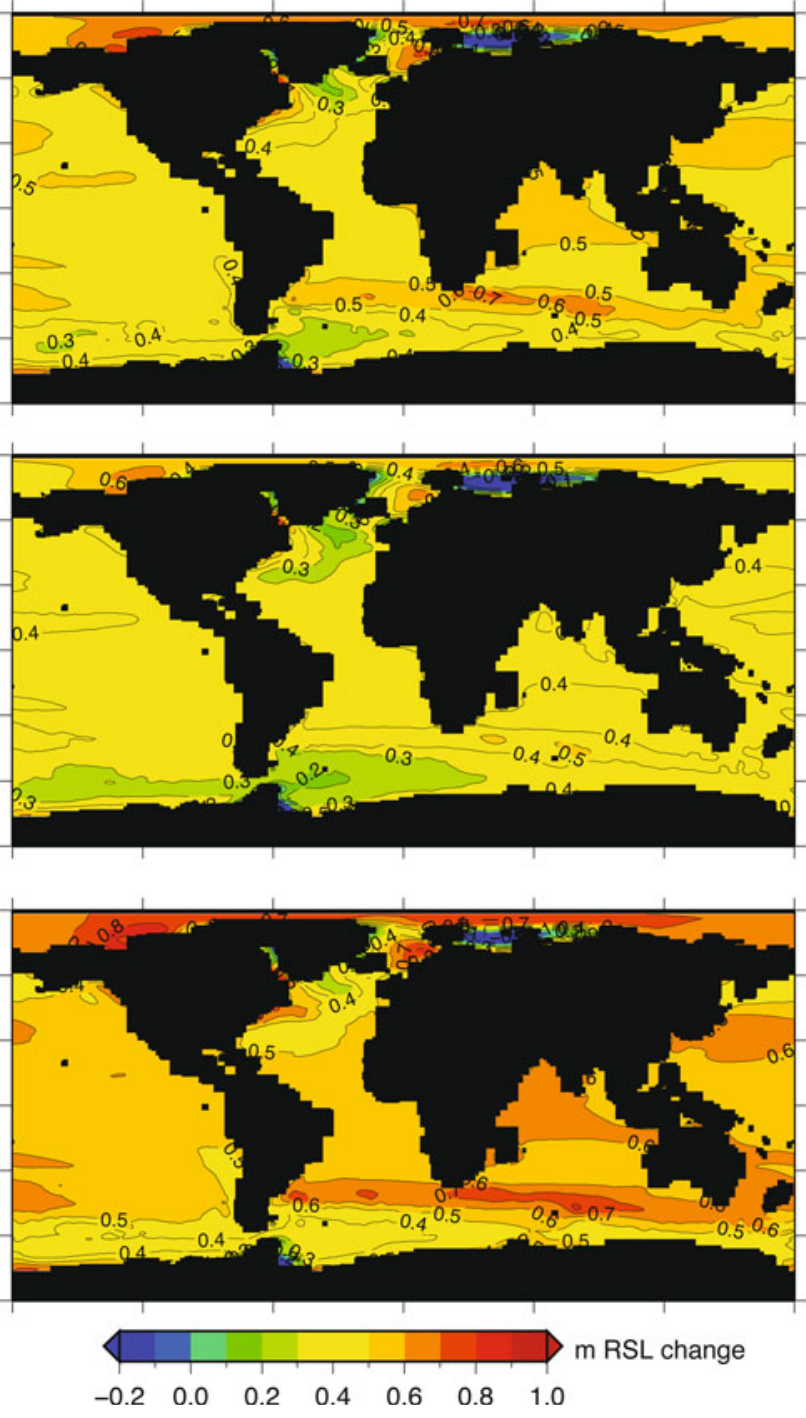

Fig. 4 Ensemble mean total RSL change (m) between 1980-1999 and 2090-2099 for scenario A1B (upper based on 12 models), B1 (middle based on 11 models) and A2 (lower based on 10 models)

added together, and the result is shown in Fig. 4 for the three scenarios: A1B (upper panel), B1 (middle panel) and A2 (lower panel). While the global mean differs (Table 4), all scenarios show a similarly large spatial variability, with no significant differences in the spatial pattern. In all three panels, the spatial variability in the steric contribution has a large impact on the ensemble mean pattern. We observe for instance in all scenarios a band of relative high RSL rise stretching from South America into the Indian Ocean. However, looking closer reveals influences of the other contributions too. The effect of Arctic freshening is less pronounced, because the steric contribution is partly balanced by the other contributions. We observe the influence of GIA for instance between Iceland and Scandinavia: the RSL change is large since this region lies on the peripheral bulge (Peltier 2004) and thus the Earth's surface is lowering here. Also future land ice melt influences the pattern, for instance in the Arctic Ocean, where it counteracts the influence of the steric changes, and around the Antarctic Peninsula, where a sea-level drop is projected as a result of the self-gravitation effect.

The total ensemble mean standard deviation of scenario A1B is shown in the lower panel of Fig. 3. Here we see that the total uncertainty, when adopting the IPCC AR4 approach for the ice sheets, is dominated by uncertainties in the steric contribution, since the values of the standard deviations of land ice and GIA are significantly smaller. Hence, the largest standard deviations can be found in the Arctic Ocean and the Southern Ocean.

Figure 5 shows how much the projection for the local sea level deviates from the ensemble mean global mean value for scenario A1B. The figure emphasizes the large spatial variability of RSL change, as it shows that the local values rarely equal the global mean value. Some regions experience a notably lower RSL, while others have extremely large RSL rise compared to the global mean, with a pattern that is qualitatively similar for all scenarios (not shown).

In order to examine the influence of the different contributions on the total projected RSL change and the spatial pattern, we show maps of the individual contributions as a fraction of the total value for A1B in Fig. 6. The upper panel shows the ratio of the steric contribution, the middle panel the land ice ratio and the lower panel the GIA ratio, all relative to the total projection. There is a large region around the equator which shows very little influence of GIA and a 50-50\% contribution for land ice and steric contributions. In the Arctic Ocean, the steric contribution is slightly larger due to Arctic freshening, which is enhanced by GIA but balanced by a relatively low contribution of land ice mass loss. Around Antarctica there is a large band where the steric contribution has relatively little influence (10-30\%), and land ice mass loss for a large part explains future RSL change in that region (60-80\%).

The ensemble mean total projection of $\mathrm{A} 1 \mathrm{~B}$ is an average of 12 AOGCM's. The total projected RSL change for each AOGCM (for A1B) with their model-specific land-sea mask, is shown in Fig. 7. Most AOGCM's show a pattern fairly similar to the ensemble mean, with slightly more spatial variation, which is smoothed in the ensemble mean. However, some models show overall higher values for RSL change [MIROC3.2(hires)], while others are below the ensemble mean (NCAR-PCM and MRICGCM2.3.2). The differences in spatial patterns between the models arise mainly from the steric component, because the land ice contribution pattern is fairly similar for all AOGCM's as the amount of ice melt may vary depending on the temperature and precipitation change, but the locations do not change. The steric component on the 
other hand is largely influenced by the way small-scale processes in the ocean, like for example ocean heat uptake, are treated in the coupled models (e.g., Yin et al. 2010; Pardaens et al. 2010). Differences in amplitude between the AOGCM's, however, may be caused by steric as well as land ice mass changes, since both contributions respond to temperature changes prescribed by the AOGCM's.

\subsection{Projections for selected coastal locations}

To further illustrate the large spatial variability in RSL change, we selected a few coastal locations and compared their local RSL change values for the land ice, steric and GIA contributions (Fig. 8a) and the total RSL change (Fig. 8b) to the global mean values. In Fig. 8 the locations are ranked from north (Reykjavik) to south (southern tip of Chile), the first 8 locations in the Northern Hemisphere, the last 5 in the Southern Hemisphere. Additionally, the global mean is provided for comparison. Values are taken from the A1B ensemble mean (Figs. 2, 4).

In Fig. 8a, large variations can be observed for the land ice contribution. Locations like Vancouver, New York and the southern tip of Chile are below the land ice global mean of $0.25 \mathrm{~m}$ because they are close to large melt sources. Reykjavik even shows a negative value. On the other hand, Hawaii, Maldives and Tahiti experience values above the global mean due to their large distance from the land ice. The steric contribution shows high values for New York, Maldives and Tasmania, and low values for Miami and southern Chile, compared to the steric global mean of $0.21 \mathrm{~m}$. Furthermore, in Fig. 8a we see that the GIA (ICE-5G) contribution is large for Vancouver, New York and Chile, compared to the global mean of $0.004 \mathrm{~m}$. Vancouver and New York are in the peripheral bulge area, which means that these locations are still subsiding as a result of the melt of the ice sheets 20,000 years ago,

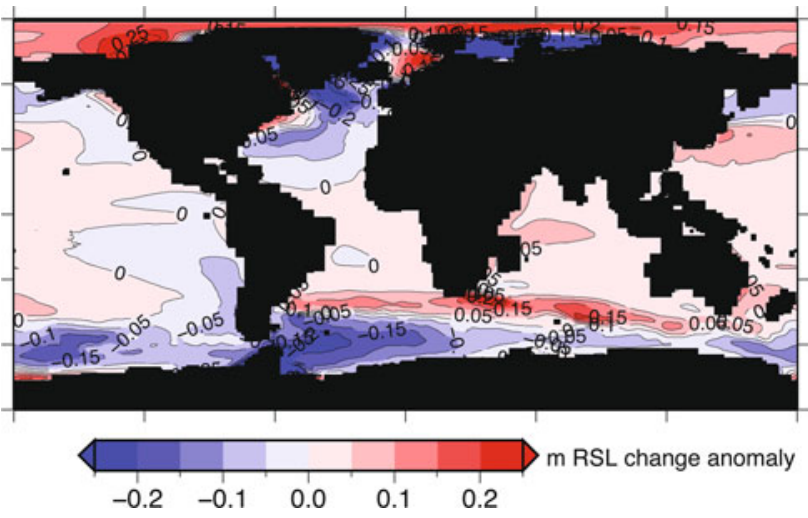

Fig. 5 Ensemble mean sea-level anomaly (m) w.r.t. global mean RSL change $(0.47 \mathrm{~m})$ for scenario A1B between 1980-1999 and 2090-2099
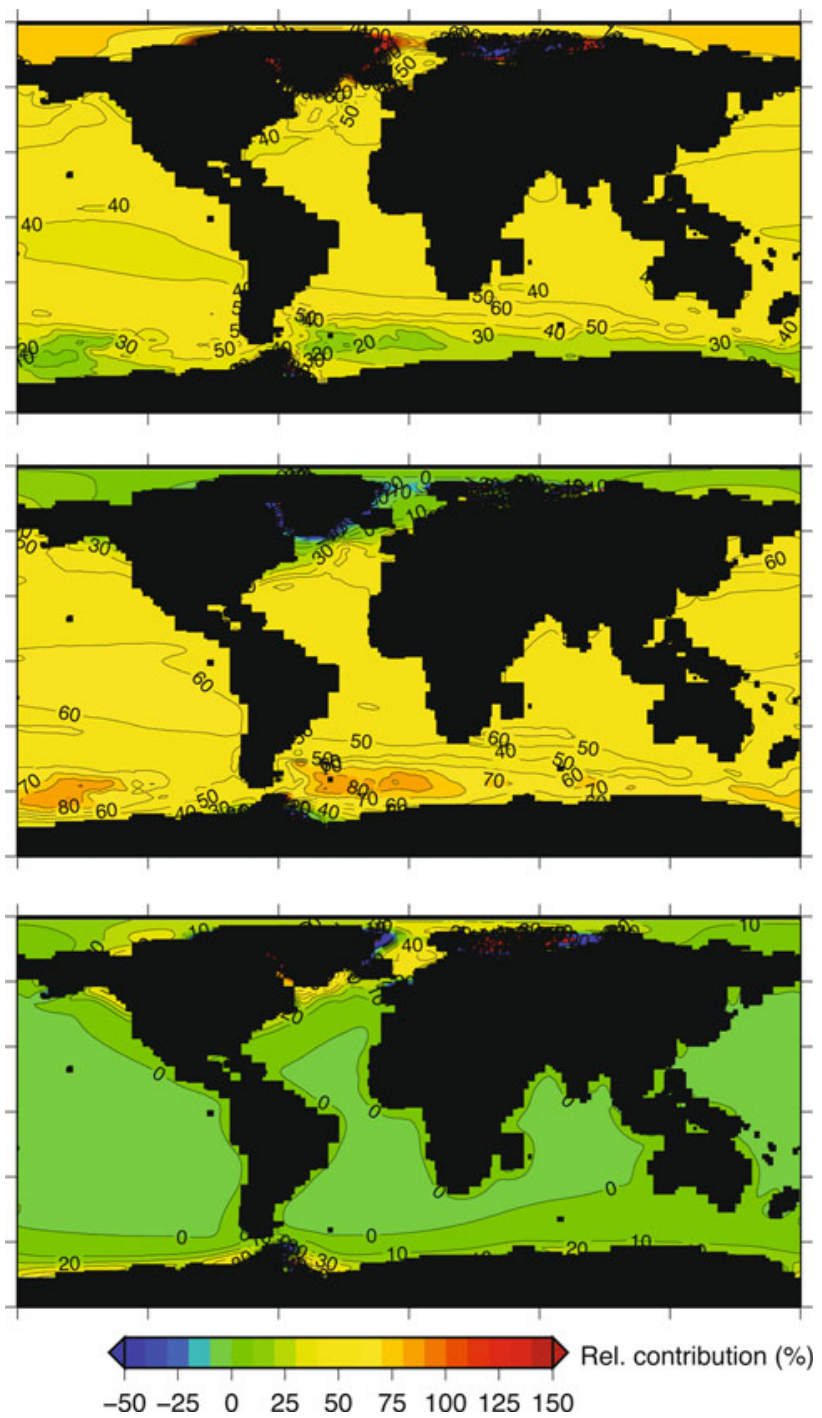

Fig. 6 Ratio (\%) between the steric (upper), land ice (middle) and GIA (lower) contributions (Fig. 2), and the ensemble mean RSL change (Fig. 4, upper panel)

resulting in a rising RSL. Reykjavik on the other hand is inside the crustal uplift area and thus experiences an RSL drop.

The sum of the contributions is given in Fig. 8b, with an uncertainty of 1 standard deviation, as in Fig. 3. All locations which are situated relatively far from land ice melt sources experience values around or above the global mean value of $0.47 \mathrm{~m}$. The largest deviations from the global mean occur in the regions closer to the ice sheets, for instance in Southern Chile, which has a smaller land ice contribution because it is close to the Patagonian Icefields and Antarctica. The results presented here illustrate that RSL change is not just a process with large spatial variations, but also that different contributions may dominate the local RSL change depending on the location. Therefore none of the contributions can be 


\section{BCCR-BCM2.0}

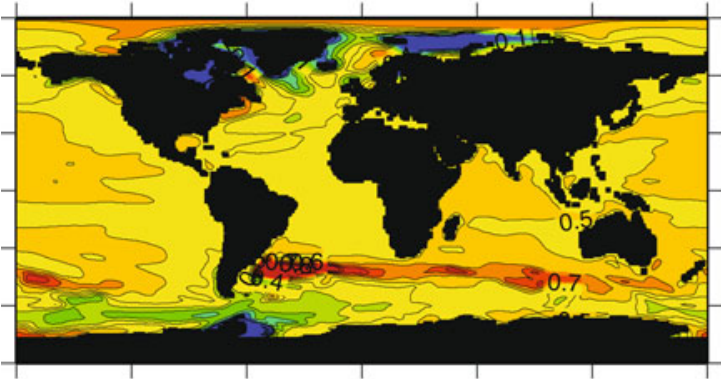

CGCM3.1(T47)

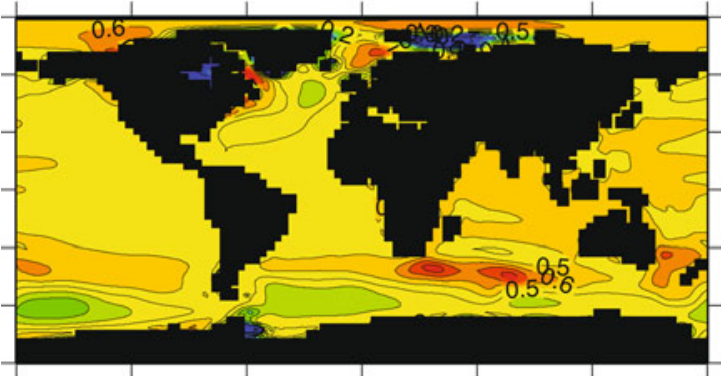

ECHAM5/MPI-OM

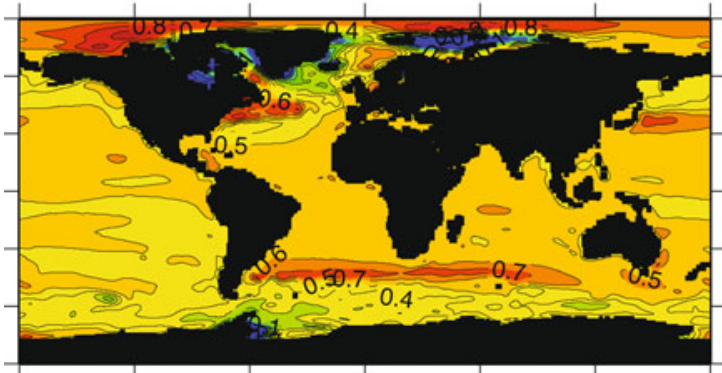

GFDL-CM2.0

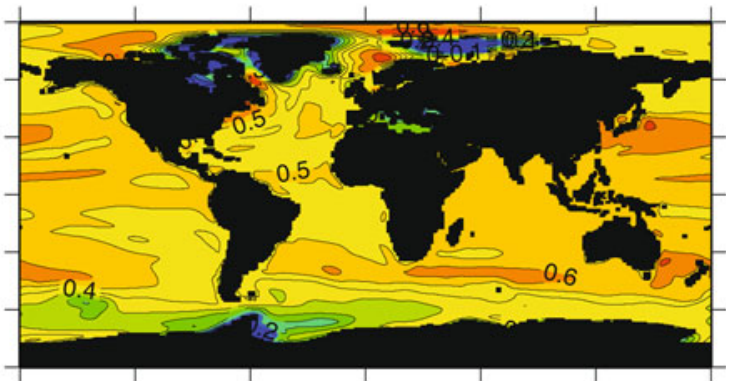

GFDL-CM2.1

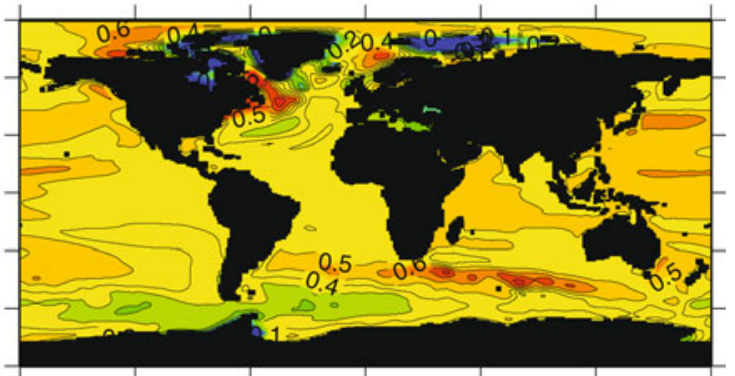

GISS-EH

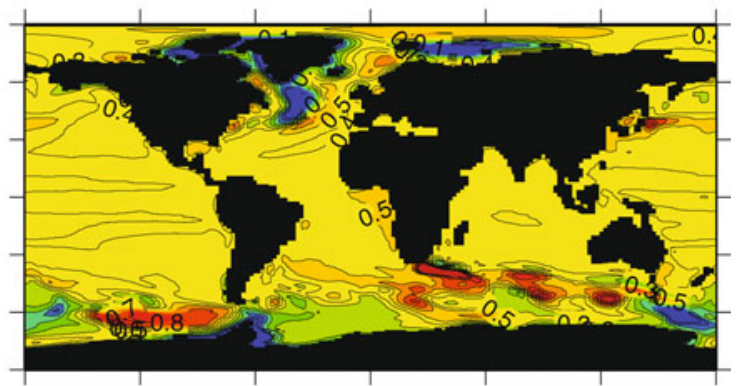

$\mathrm{m}$ RSL change

\section{$\begin{array}{lllllll}-0.2 & 0.0 & 0.2 & 0.4 & 0.6 & 0.8 & 1.0\end{array}$}

Fig. 7 Total RSL change (m) between 1980-1999 and 2090-2099 for the individual AOGCM's in Table 2 for scenario A1B

neglected when determining spatial patterns of total RSL change.

\section{Discussion of regional sea-level projections}

\subsection{Discussion of contributions included in this study}

This study uses mostly the same data that were used in IPCC AR4, with the exception of the input data for the glacier model. This approach was taken to allow a comparison between the global mean values presented in IPCC AR4 and the regional patterns presented in this study.

For the glaciers, a database first published in 2009 was used (Radić and Hock 2010), because more detailed information was needed to model the regional influence of glaciers. In IPCC AR4 the total volume of glaciers (excluding glaciers around the GIS and the AIS) was estimated to be 0.15 (Ohmura 2004), 0.24 (Raper and Braithwaite 2005) and $0.37 \mathrm{~m}$ (Dyurgerov and Meier 2005) SLE. These three different estimates are used throughout the AR4 report. To account for glaciers around the GIS and the AIS, the land ice contribution to RSL change was multiplied with a factor 1.2. Here, the initial glacier volume is $0.6 \mathrm{~m} \mathrm{SLE}$, including glaciers around the GIS and the AIS, which is larger than each of the IPCC AR4 estimates. Radić and Hock (2010) attribute these differences to the use of different methodologies and input data. As a consequence of the use of a different data set, not only the initial volume, but also the resulting projected contribution of the glaciers is larger: IPCC AR4 projects a global mean contribution of glaciers (including those around AIS and GIS) of $0.08-0.15 \mathrm{~m}$ SLE under the A1B scenario, while this study finds $0.13-0.25 \mathrm{~m}$ SLE (5-95\% range). 
GISS-ER

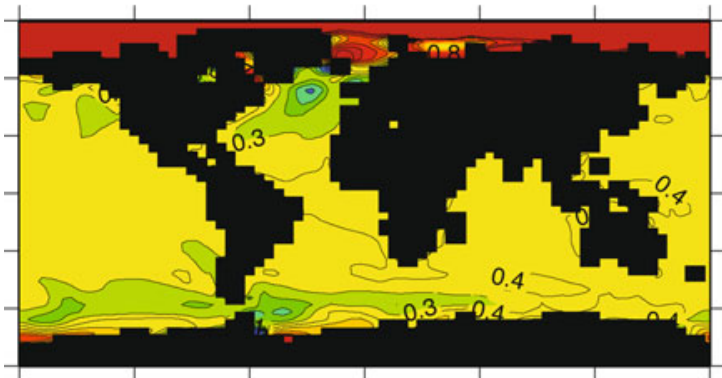

GISS-AOM

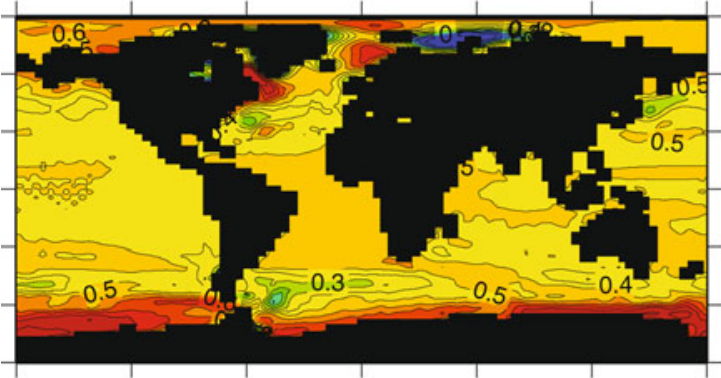

MRI-CGCM2.3.2
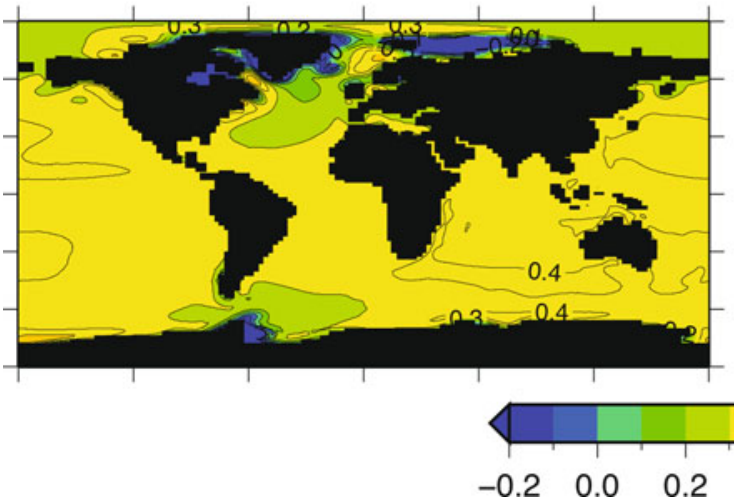

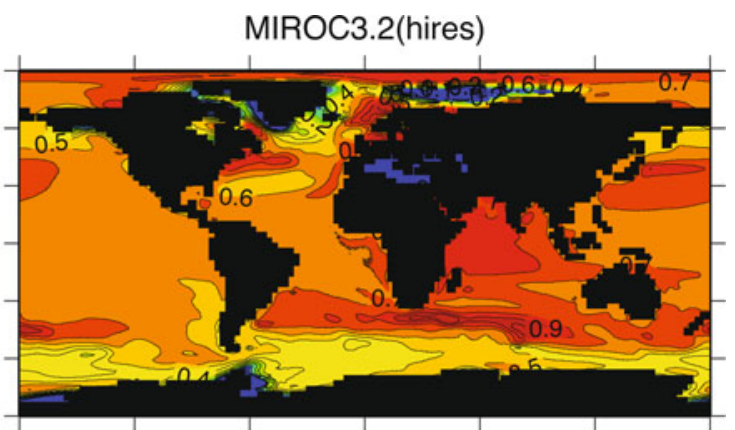

NCAR-PCM

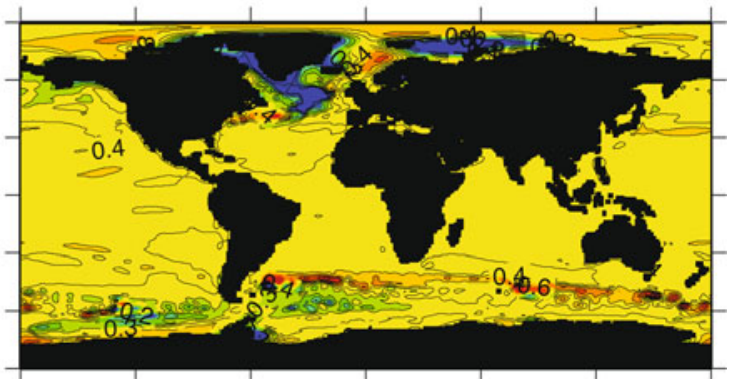

UKMO-HadCM3

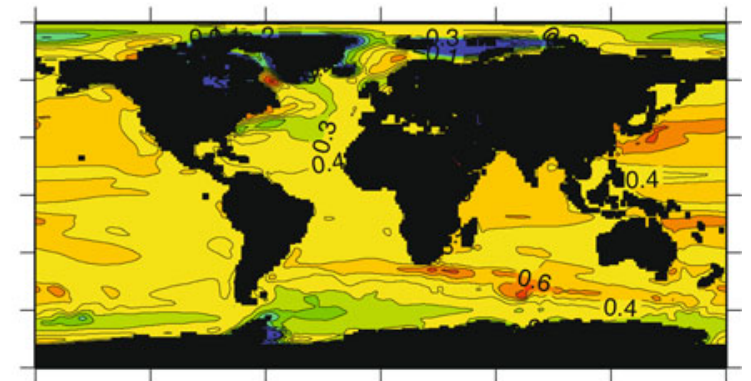

$m$ RSL change

Fig. 7 continued

To examine the influence of different glacier data on the regional pattern, we compare two glacier data sets, while keeping the same set-up of the model. Throughout this study we used the inventory by Radić and Hock (2010). The second data set is an inventory used by Van de Wal and Wild (2001), which contains 135 glacierized regions (Zuo and Oerlemans 1997; Van de Wal and Wild 2001) with an additional $10 \%$ to account for the glacier contribution of the Antarctic glaciers, as in Meehl et al. (2007b). The Van de Wal and Wild (2001) data has a smaller initial total glacier volume than the Radić and Hock (2010) data ( 0.50 and $0.60 \mathrm{~m}$, respectively), but we find that the contribution of glaciers to future RSL change depends on the data set rather than on the initial glacier volume, as the Van de Wal and Wild-contribution is only $0.01 \mathrm{~m}$ SLE larger.
The main difference between the Radić and Hock data and the Van de Wal and Wild data is a larger amount of mass loss near GIS and less mass loss around AIS. This results in lower values in the Arctic Ocean and higher values $(+0.02 \mathrm{~m})$ in the Indian Ocean and the Southern Pacific. However, the RSL change pattern is fairly similar to Fig. 2 (upper right panel). Hence, we conclude that while the absolute values differ in some locations, the pattern will not change significantly when the main melt sources are situated in the same locations, which is the case for these two glacier data sets.

For the future contribution of the ice sheets, calculations were performed similar to the computations in IPCC AR4, with only one small modification. To calculate the spatial distribution of the dynamical SMB change and the scaled- 


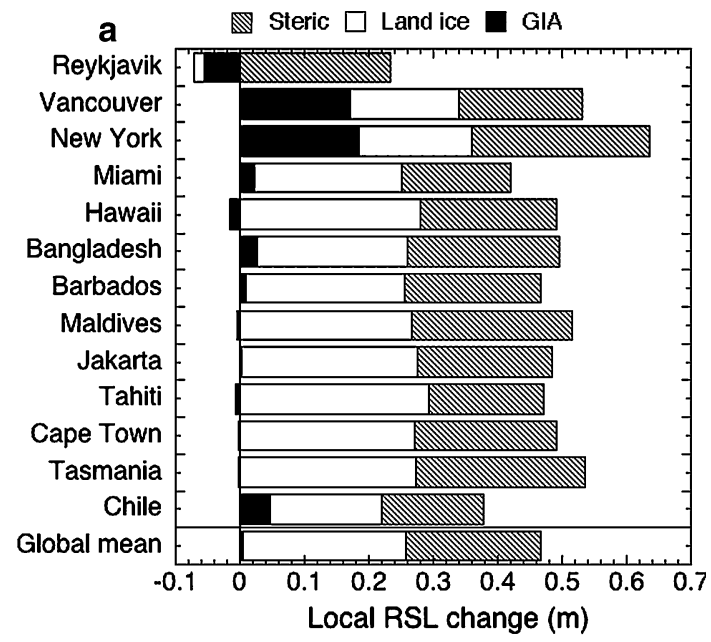

b

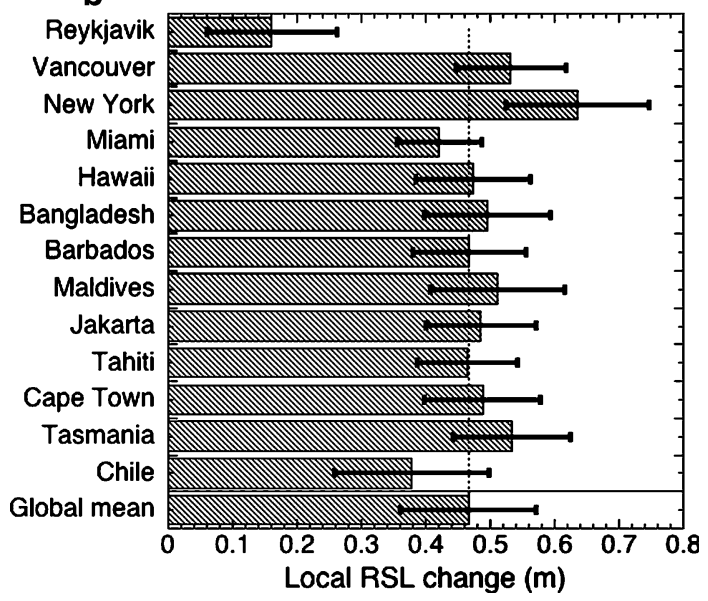

Fig. 8 Projection of local RSL change (m) for selected coastal cities between 1980-1999 and 2090-2099 for scenario A1B. a Contributions: Steric (grey), Land ice (white) and GIA (black). b Total RSL change and associated $1 \sigma$ uncertainty

up ice sheet discharge, the contributions needed to be calculated separately for each ice sheet, instead of using one value for both ice sheets combined, as in the IPCC AR4 report.

Although the results reported in IPCC AR4 were the state of the art on climate change in 2007, recent research has updated the estimates and models of different aspects regarding climate change. Nevertheless, we deliberately chose to stay as close as possible to the AR4 report in order to allow for a comparison of the spatial patterns to the wellknown IPCC AR4 global mean values. To illustrate how this choice influences the results, we recalculated the RSL change with larger estimates for the contributions of the ice sheets, as recent observations show a faster increase in mass loss than estimated in IPCC AR4 (e.g., Rignot et al. 2008a, b, 2011; Velicogna 2009). For this example, we use a high-end estimate of $0.41 \mathrm{~m}$ SLE for the AIS and $0.22 \mathrm{~m}$ SLE for the GIS, as suggested by Katsman et al. (2010) based on a reassessment of the dynamical contribution of the ice sheets considering recent observations and expert judgement. Contrarily to the calculations done in Sect. 3, the ice sheet contribution is now fixed and thus not dependent on the temperature and precipitation provided by the climate models. This means that an ensemble spread could not be calculated for this experiment. However, as the contribution of the ice sheets is much larger than in Sect. 3, it will probably show larger variations for differences in climate, which would lead to a larger spread than displayed in Fig. 3, but it is uncertain how much this would differ exactly. All the other contributions are the same as presented in Table 4 and Fig. 2, the A1B scenario. Adding all the contributions now leads to a global mean RSL change of $1.02 \mathrm{~m}$ SLE. The resulting anomaly with respect to the ensemble global mean RSL change is shown in Fig. 9. The ice sheets now account for $60 \%$ of the total RSL change instead of only $25 \%$ in the IPCC AR4. This clearly influences the pattern in Fig. 9, compared to Fig. 5. The large amount of land ice melt on both ice sheets causes large sea-level drop regions around them. Also, the RSL rise around the equator is much larger due to the selfgravitation effect. These effects are also shown in e.g. Bamber and Riva (2010) and Riva et al. (2010) and are a direct consequence of the gravitational attraction. The steric contribution now only accounts for $20 \%$ of the global mean instead of $45 \%$, which means that the land ice melt is the dominant contribution. Still, features of the steric component and the GIA remain present, but less pronounced.

The example shown in Fig. 9 illustrates the importance of using the best estimates possible when calculating regional RSL variations, as the total pattern in RSL change depends on the pattern from each of the contributions. Therefore, in the future, our model strategy can easily be used with better estimations for Greenland mass change (e.g., Fettweis et al. 2008; Rignot et al. 2008b; Van den

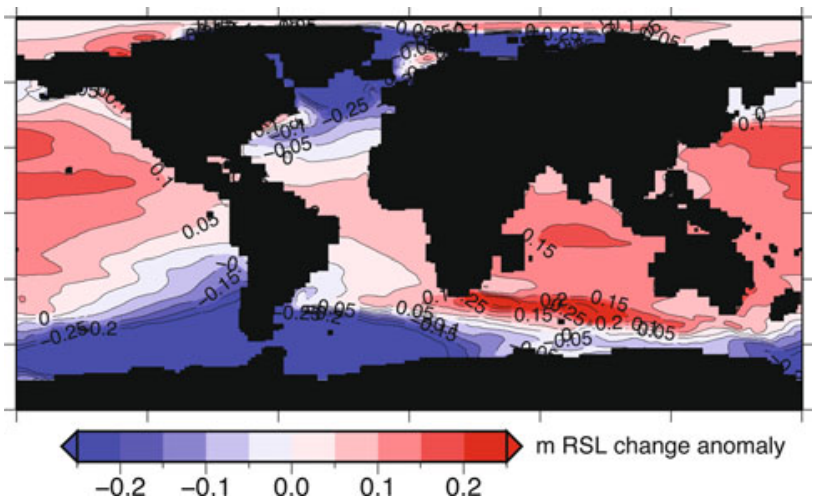

Fig. 9 Ensemble mean sea-level anomaly (m) w.r.t. global mean RSL change $(1.02 \mathrm{~m})$ for scenario A1B between 1980-1999 and 2090-2099, for a scenario with adapted ice sheet contributions of $0.22 \mathrm{~m}$ for GIS and $0.41 \mathrm{~m}$ for AIS 
Broeke et al. 2009; Ettema et al. 2009), different values for Antarctic mass change (e.g., Rignot et al. 2008a; Bamber et al. 2009; Velicogna 2009) or different steric fields from a new generation of climate models and improved data sets. Additionally, increasing the number of glaciers described in databases and the development of global glacier models will improve the estimation of the glacier contribution to RSL change for the next century.

For the estimate of the GIA-contribution (Sect. 2.3) we arbitrarily chose to calculate the projections based on the ICE-5G (VM2) model. We will now show the consequence of using a different GIA model, namely the ANU model (Nakada and Lambeck 1988, updated in 2004-2005). Figure 10 is similar to Fig. 8, but now the GIA contribution is from the ANU model, and only those locations are shown where GIA is large. In Fig. 10a the GIA contribution according to the ANU model shows a larger sea-level rise near Reykjavik and Miami, which is substantially different from the ICE-5G GIA. Reykjavik is placed in an uplift area in the ICE-5G model, but in an area which is subsiding in the ANU-model. The region around the former ice sheets currently experiencing a sea-level rise due to GIA is much larger in the ANU-model, which explains the large values for Miami and Chile. The differences between the two models are partly caused by the ice histories used, but more importantly by different mantle viscosities, resulting in deviating present-day rates of GIA. Vancouver and New York both have a large positive contribution of GIA, resulting in an above-mean RSL change, as shown in Fig. 8b. The negative land ice contribution for Reykjavik is
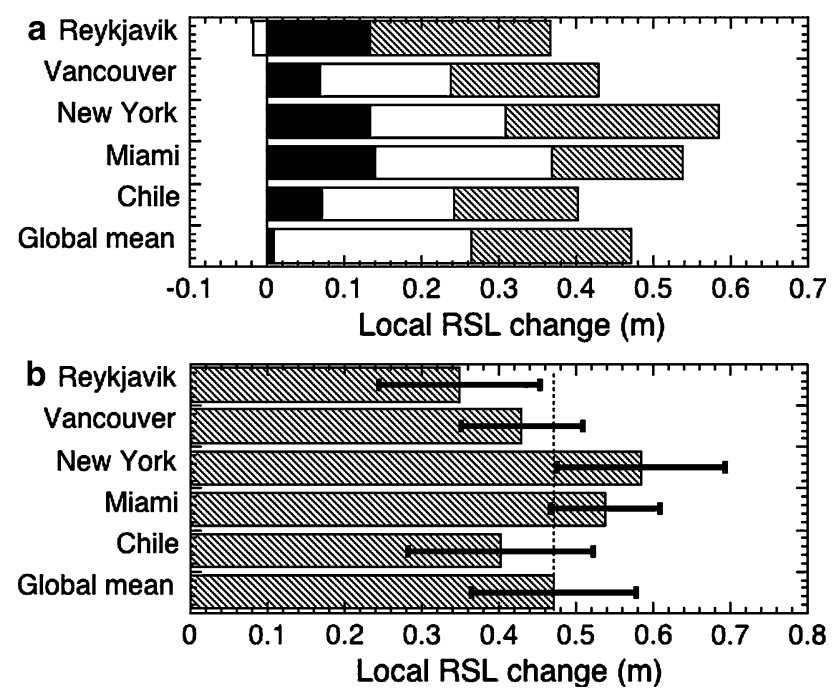

Fig. 10 Projection of local RSL change (m) for selected coastal cities between 1980-1999 and 2090-2099 for scenario A1B with GIA contribution from ANU (updated version of Nakada and Lambeck 1988). a Contributions: Steric (grey), Land ice (white) and GIA (black). b Total RSL change and associated $1 \sigma$ uncertainty compensated by a very large positive GIA contribution, but the total RSL change is still below average.

Both global GIA models are mainly based on sea-level indicators, like sediment cores and corals, that are sparsely distributed and difficult to date accurately. Therefore, differences as in Figs. 8 and 10 occur. Recent efforts that will help to reduce the current GIA uncertainty include for instance the use of space-geodesy (e.g. King et al. 2010).

\subsection{Discussion of contributions not included in this study}

A factor that influences local RSL change but is not considered in this study is the response of the ocean circulation to land ice changes, in the form of melt water run-off being added to the ocean. In order to model the effects of freshwater addition to the ocean due to land ice melt, coupled climate models need to be equipped with an interactive land ice module. The current generation of coupled climate models does not yet have this feature and hence this effect has been omitted from the local projections presented in this study.

From dedicated numerical simulations (so-called hosing experiments) it has been known for a quite a while that the effect of melt water on the ocean circulation can be substantial (Manabe and Stouffer 1995; Vellinga and Wood 2002) and has notable effects on local sea level (Yin et al. 2010). However, the amount of melt water added to the ocean in these experiments is much larger than current observations of ice sheet mass loss suggest to be appropriate for the next century. Using a more realistic estimate for the imbalance of the Greenland ice sheet, Stammer (2008) found that the added fresh water will induce sea surface height variations of a couple of centimeters after 50 years, mainly in the North Atlantic Ocean. As pointed out by Gower (2010), this is only the steric response of the global ocean circulation to freshwater forcing around the Greenland ice sheet, as the forcing is not applied by adding fresh water but by removing salt at the ocean surface (Gower 2010; Stammer 2010). However, from comparative hosing experiments by Yin et al. (2010) it appears that either adding fresh water or removing salt yields very similar results with regard to regional variations in sea level. The results for global mean sea level obviously differ by the amount of fresh water that is added using the former method. Although it needs to be confirmed that this also holds for ocean freshening due to melt water originating from Antarctica, this indicates that it is in fact feasible to investigate the effect of melt water run-off on local sea level in a partially coupled, consistent way by applying an appropriate fresh water flux obtained from an ice sheet model. The magnitude of the response seen by Stammer (2008) suggests that this is a second-order effect for 
realistic ice sheet contributions. However, these type of simulations are not yet available for the time period considered in this study and hence cannot be included.

Other contributions we do not consider here are variations in terrestrial water storage, such as water impoundment behind dams (Fiedler and Conrad 2010) or groundwater mining (Wada et al. 2010). Fiedler and Conrad (2010) report a global average RSL drop of approximately $30 \mathrm{~mm}$ over the twentieth century, while Wada et al. (2010) find an average RSL rise of $0.8 \mathrm{~mm} /$ year due to groundwater mining. Although potentially important, neither of these studies provide projections for the twentyfirst century.

\subsection{Discussion of the climate model ensemble}

The ensemble mean for A1B used in this study consists of 12 AOGCM's, while for the A2 and B1 scenarios an ensemble of respectively 10 and 11 AOGCM's has been used. For each scenario this is the largest ensemble for which all the required input variables are available (Sect. 2). Using the same 10 AOGCM's for all scenarios results (for A1B) in a total projected RSL change of $0.45 \pm 0.10 \mathrm{~m}$ instead of $0.47 \pm 0.11 \mathrm{~m}$, and the spatial pattern barely changes. Therefore, we considered it appropriate to use the largest available ensemble of 12 AOGCM's for the analyses presented in Sect. 3 rather than using only the overlapping AOGCM simulations.

The model spread in the total projection, which is based almost entirely on data used for the IPCC AR4 projections, is dominated by the spread in the steric changes (Fig. 3). In particular, in the Arctic and in the Southern Ocean the ensemble displays a large spread with a standard deviation exceeding $0.3 \mathrm{~m}$. For local planning purposes, it would be beneficial if the large uncertainty in the local projection could be reduced by some form of quality control applied to the model ensemble. One example for a measure of the model skills is the ability of coupled climate models to simulate present-day dynamic sea-level patterns. Yin et al. (2010) analysed the rootmean-square difference between the observed and modelled sea-level patterns for seventeen climate models over the twentieth century, and excluded five models from their study based on this analysis. Four of these models are also part of our model ensemble (GISS-EH, GISS-AOM, MRICGCM2.3.2 and NCAR-PCM). An analysis of $Q$, defined as the difference between the ensemble mean and the model-specific steric contribution, normalized by the local standard deviation,

$Q(x, y)=a b s\left[S L_{\text {steric }}(x, y)-\overline{S L_{\text {steric }}(x, y)}\right] / \sigma(x, y)$

reveals that GISS-EH and GISS-AOM are clearly outliers in the model ensemble in the Arctic and Southern Ocean, respectively, with values of $Q>2.5$ over the largest part of these areas. None of the other models have $Q$ values comparable to this. In contrast, even though according to the analysis presented by Yin et al. (2010) they have poor skills in reproducing present-day sea-level patterns, MRICGCM2.3.2 and NCAR-PCM are not outliers in the model ensemble when $Q$ is considered as a measure. This indicates that the future change in RSL they project is comparable to that of the other models.

When the four models indentified by Yin et al. (2010) are omitted from the model ensemble, the global mean contribution of the expansion and the global mean standard deviation of the steric component changes from $0.21 \pm 0.09$ to $0.22 \pm 0.09 \mathrm{~m}$. However, the local standard deviation in the polar regions reduces considerably to sigma values of about $0.15 \mathrm{~m}$ rather than $0.40 \mathrm{~m}$ if all 12 models are included. In the Arctic, also the ensemble mean value reduces considerably.

The above analysis illustrates how large the impact of individual models on the variability can be, and hence the need for performing some type of quality control on the model results. Analyses like the one presented by Yin et al. (2010) can be a way forward to reduce the uncertainty in local projections, when the proper physical processes that cause the sea-level patterns are considered and understood (Landerer et al. 2007; Pardaens et al. 2010).

\section{Summary and conclusions}

Sea-level change as a result of a changing climate is often regarded as a globally uniform process, with the same sealevel rise occuring everywhere. Clearly this is not the case: the spatial variability in the different contributions to relative sea-level (RSL) change is very large (Fig. 2). For governments and policy makers this is vital information to determine whether measures have to be taken to protect coastal communities from sea-level rise.

Instead of characterizing RSL change by a single number, we have used several models to calculate spatial distributions of the different contributions to RSL change. As a starting point, we used the same data as in IPCC AR4, except from the glacier data base. We coupled a volumearea model (Sect. 2.1.1) and estimations of ice sheet contributions (Sect. 2.1.2) with a sea-level model (Sect. 2.1.3) to compute the influence of the location and amount of melting land ice on the sea level. This was done for an ensemble of 12 coupled climate models and 3 emission scenarios with varying temperature and precipitation (Sect. 2.4). To estimate the steric contribution (changes in density and resulting changes in ocean dynamics, Sect. 2.2) we used the output from the same ensemble of coupled climate models. For the GIA, which is not influenced by the current 
climate but a result of climate change 20,000 years ago, we used results of a glaciation-deglaciation model to estimate the influence on RSL change (Sect. 2.3).

In most regions, the two largest contributions are the addition of mass (the land ice component) and the changes in density (the steric component), while GIA is only large in some specific areas (Fig. 2). The steric component shows very large spatial variations, because changes in density occur when ocean currents change, fresh water is added or atmospheric temperature changes. The land ice contribution on the other hand also shows large variations, but with a distinctive pattern due to elastic solid Earth deformation and the self-gravitation effect. Globally averaged, both the land ice contribution and the steric contribution account individually for about $50 \%$ of the RSL change (Table 4). However, considering the total projected spatial pattern reveals that all contributions included in this study, even GIA, can dominate the local RSL change, depending on the location (Figs. 4, 8). The amplitudes of the local RSL change differ per scenario, but the patterns are fairly similar. The spread in the local RSL change for the projection based on the data used in IPCC AR4 is dominated by the spread in the steric contribution between the different AOGCM's, while the uncertainty in the land ice contribution is largest close to the land ice melt source and fairly small otherwise (Fig. 3). An increase in the estimation of the ice sheet contribution might also increase the spread for this contribution, but it is uncertain whether the result will be as large as the spread in the steric contribution.

The absolute values presented in this study should be interpreted carefully. In Sect. 4.1 we have shown that following the approach taken by IPCC AR4 introduces a potential underestimation in the ice sheet contributions, which would influence the pattern substantially (Fig. 9). This section also discusses the choice of GIA model, which is a small contribution when globally averaged, but can dominate RSL change locally. Additionally, this section shows that the projections are not very sensitive to the choice of glacier data set.

We have shown with this study that it is possible to model regional variability in future RSL change, by using a combination of spatial patterns of steric effects, land ice melt and GIA obtained from different models. Improvements can be made, for instance by adding a coupling between ice melt and ocean dynamics or by better estimates for the land ice melt. Irrespective of the details in methodology, we think that scientific understanding now allows to discuss regional patterns rather than only the global mean values.

Acknowledgments We would like to thank J. Gregory for providing the SMB constants and the additional expansion data, V. Radic for help with the WGI-XF data and J. Cogley for making this dataset available. We would also like to thank P. Stocchi and K. Lambeck for providing us with the ANU model. We acknowledge the international modeling groups for providing their data for analysis, the Program for Climate Model Diagnosis and Intercomparison (PCMDI) for collecting and archiving the model data, the JSC/CLIVAR Working Group on Coupled Modelling (WGCM) and their Coupled Model Intercomparison Project (CMIP) and Climate Simulation Panel for organizing the model data analysis activity, and the IPCC WG1 TSU for technical support. A.S is supported by the Netherlands Institute for Space Research (SRON) (ALW-GO-AO/07-14). We thank two anonymous reviewers for their useful comments.

Open Access This article is distributed under the terms of the Creative Commons Attribution Noncommercial License which permits any noncommercial use, distribution, and reproduction in any medium, provided the original author(s) and source are credited.

\section{References}

Antonov JI, Levitus S, Boyer TP (2002) Steric sea level variations during 1957-1994: importance of salinity. J Geophys Res 107(C12):8013. doi:10.1029/2001JC000,964

Bahr DB, Meier MF, Peckham SD (1997) The physical basis of glacier volume-area scaling. J Geophys Res 102(B9): 20,355-20,362

Bamber J, Riva R (2010) The sea level fingerprint of recent ice mass fluxes. Cryosphere 4:621-627. doi:10.5194/tc-4-621-2010

Bamber JL, Riva REM, Vermeersen LLA, LeBrocq AM (2009) Reassessment of the potential sea-level rise from a collapse of the West Antarctic ice sheet. Science 324:901-903

Bindoff NL, Willebrand J, Artale V, Cazenave A, Gregory J, Gulev S, Hanawa K, Quéré CL, Levitus S, Nojiri Y, Shum CK, Talley LD, Unnikrishnan A (2007) Observations: oceanic climate change and sea level. In: Solomon S, Qin D, Manning M, Chen Z, Marquis M, Averyt KB, Tignor M, Miller HL (eds) Climate change 2007: the physical science basis. Contribution of working group I to the 4th assessment report of the intergovernmental panel on climate change. Cambridge University Press, Cambridge

Cazenave A, Nerem RS (2004) Present-day sea level change: observations and causes. Rev Geophys 42(RG3001)

Cazenave A, Dominh K, Guinehut S, Berthier E, Llovel W, Ramilien G, Ablain M, Larnicol G (2009) Sea level budget over 2003-2008. A reevaluation from GRACE space gravimetry, satellite altimetry and ARGO. Glob Planet Change 65:83-88. doi:10.1016/j.gloplacha.2008.10.004

Chen J, Ohmura A (1990) Estimation of Alpine glacier water resources and their change since the 1870's. IAHS 193:127-135

Cogley JG (2009) A more complete version of the World Glacier Inventory. Ann Glaciol 50:32-38

Delworth TL, Broccoli AJ, Rosati A, Stouffer RJ, Balaji V, Beesley JA, Cooke WF, Dixon KW, Dunne J, Dunne KA, Durachta JW, Findell KL, Ginoux P, Gnanadesikan A, Gordon CT, Griffies SM, Gudgel R, Harrison MJ, Held IM, Hemler RS, Horowitz LW, Klein SA, Knutson TR, Kushner PJ, Langenhorst AR, Lee HC, Lin SJ, Lu J, Malyshev SL, Milly PCD, Ramaswamy V, Russell J, Schwarzkopf MD, Shevliakova E, Sirutis JJ, Spelman MJ, Stern WF, Winton M, Wittenberg AT, Wyman B, Zeng F, Zhang R (2006) GFDL's CM2 global coupled climate models. Part I: formulation and simulation characteristics. J Clim 19:643-674 
Dyurgerov MB, Meier MF (2005) Glaciers and the changing earth system: a 2004 snapshot. Tech. rep., Inst. of Arct. and Alp. Res., Univ. of Colo., Boulder, Occas Pap No 58

Dziewonski AM, Anderson DL (1981) Preliminary reference Earth model. Phys Earth Planet Inter 25:297-356

Ettema J, van den Broeke MR, van Meijgaard E, van de Berg WJ, Bamber JL, Box JE, Bales RC (2009) Higher surface mass balance of the Greenland ice sheet revealed by high-resolution climate modeling. Geophys Res Lett 36(12). doi: 10.1029/2009 GL038110

Farrell WE, Clark JA (1976) On postglacial sea level. Geophys J R Astron Soc 46:647-667

Fettweis X, Hanna E, Gallée H, Huybrechts P, Erpicum M (2008) Estimation of the Greenland ice sheet surface mass balance for the 20th and 21st centuries. Cryosphere 2(2):117-129. doi: $10.5194 / \mathrm{tc}-2-117-2008$

Fiedler JW, Conrad CP (2010) Spatial variability of sea level rise due to water impoundment behind dams. Geophys Res Lett 37(L12603). doi:10.1029/2010GL043462

Flato GM (2005) The third generation coupled global climate model (CGCM3). http://www.cccma.ec.gc.ca/models/cgcm3.shtml

Furevik T, Bentsen M, Drange H, Kvamsto N, Sorteberg A (2003) Description and evaluation of the Bergen climate model: ARPEGE coupled with MICOM. Clim Dyn 21:27-51

Gomez N, Mitrovica JX, Tamisiea ME, Clark PU (2010) A new projection of sea level change in response to collapse of marine sectors of the Antarctic Ice Sheet. Geophys J Int 180:623-634. doi:10.1111/j.1365-246X.2009.04419.x

Gordon C, Cooper C, Senior CA, Banks HT, Gregory JM, Johns TC, Mitchell JFB, Wood RA (2000) The simulation of SST, sea ice extents and ocean heat transports in a version of the Hadley Centre coupled model without flux adjustments. Clim Dyn $16: 147-168$

Gower JFR (2010) Comment on "Response of the global ocean to Greenland and Antarctic ice melting"; by D. Stammer. J Geophys Res 115(C10009). doi:10.1029/2010JC006097

Gregory JM, Huybrechts P (2006) Ice-sheet contributions to future sea-level change. Phil Trans R Soc A 364:1709-1731. doi: 10.1098/rsta.2006.1796

Jungclaus JH, Keenlyside N, Botzet M, Haak H, Luo JJ, Latif M, Marotzke J, Mikolajewicz U, Roeckner E (2006) Ocean circulation and tropical variability in the coupled model ECHAM5/MPI-OM. J Clim 19:3952-3972

K-1 Model Developers (2004) K-1 coupled model (MIROC) description. Tech rep 1, Center for Climate System Research, University of Tokyo

Katsman CA, Sterl A, Beersma JJ, van den Brink HW, Church JA, Hazeleger W, Kopp RE, Kroon D, Kwadijk J, Lammersen R, Lowe J, Oppenheimer M, Plag H.-P., Ridley J, von Storch H, Vaughan DG, Vellinga P, Vermeersen LLA, van de Wal RSW, Weisse R (2010) Exploring high-end scenarios for local sea level rise to develop flood protection strategies for a low-lying delta the Netherlands as an example. Clim Change (in press)

King M, Altamimi Z, Boehm J, Bos M, Dach R, Elosegui P, Fund F, Hernández-Pajares M, Lavallée D, Cerveira PM, Penna N, Riva $\mathrm{R}$, Steigenberger P, van Dam T, Vittuari L, Williams S, Willis P (2010) Improved constraints to models of glacial isostatic adjustment: a review of the contribution of ground-based geodetic observations. Surv Geophys 31(5):465-507. doi: 10.1007/s10712-010-9100-4

Landerer FW, Jungclaus JH, Marotzke J (2007) Regional dynamic and steric sea level change in response to the IPCC-A1B scenario. J Phys Oceanogr 37:296-312

Lemke P, Ren J, Alley RB, Allison I, Carrasco J, Flato G, Fujii Y, Kaser G, Mote P, Thomas RH, Zhang T (2007) Observations: changes in snow, ice and frozen ground. In: Solomon S, Qin D,
Manning M, Chen Z, Marquis M, Averyt KB, Tignor M, Miller HL (eds) Climate change 2007: the physical science basis. Contribution of working group I to the 4th assessment report of the intergovernmental panel on climate change. Cambridge University Press, Cambridge

Lowe JA, Gregory JM (2006) Understanding projections of sea level rise in a hadley centre coupled climate model. J Geophys Res 111(C11014). doi:10.1029/2005JC003421

Lucarini L, Russell GL (2002) Comparison of mean climate trends in the northern hemisphere between National Centers for Environmental Prediction and two atmosphere-ocean model forced runs. J Geophys Res 107(D15):4269. doi:10.1029/2001JD001247

Manabe S, Stouffer RJ (1996) Simulation of abrupt climate change induced by freshwater input to the North Atlantic Ocean. Nature 378:165-167. doi:10.1038/378165a0

Meehl GA, Covey C, Delworth T, Latif M, McAvaney B, Mitchell JFB, Stouffer RJ, Taylor KE (2007) The WCRP CMIP3 multimodel dataset: a new era in climate change research. Bull Am Meteorol Soc 88:1383-1394

Meehl GA, Stocker TF, Collins WD, Friedlingstein P, Gaye A, Gregory J, Kitoh A, Knutti R, Murphy J, Noda A, Raper S, Watterson I, Weaver A, Zhao ZC (2007b) Global climate projections. In: Solomon S, Qin D, Manning M, Chen Z, Marquis M, Averyt KB, Tignor M, Miller HL (eds), Climate change 2007: the physical science basis. Contribution of working group I to the 4th assessment report of the intergovernmental panel on climate change. Cambridge University Press, Cambridge

Millard RC, Mamayev O, Fofonoff N, Gieskes JM, Lafond E, Lewis EL, Millero FJ, Morcis S, Perkin R, Poisson A, Reid JL (1987) International oceanographic tables. Unesco tech pap mar sci 4

Milne GA, Mitrovica JX (1998) Postglacial sea-level change on a rotating Earth. Geophys J Int 133:1-19

Mitrovica JX, Peltier WR (1991) On postglacial geoid subsidence over the equatorial oceans. J Geophys Res 96(B12):20,053-20,071

Mitrovica JX, Tamisiea ME, Davis JL, Milne GA (2001) Recent mass balance of polar ice sheets inferred from patterns of global sealevel change. Nature 409:1026-1029

Nakada M, Lambeck K (1988) The melting history of the late Pleistocene Antarctic ice sheet. Nature 333:36-40

Nakicenovic, N, Swart, R (eds) (2000) Emission scenarios. Cambridge University Press, Cambridge

Nicholls RJ, Cazenave A (2010) Sea-level rise and its impact on coastal zones. Science 328(5985):1517-1520. doi:10.1126/ science. 1185782

Ohmura A (2004) Cryosphere during the twentieth century. In: Sparks RSJ, Hawkesworth CJ (eds) The state of the planet: frontiers and challenges in geophysics. Geophys. Monogr. Ser., vol 150. AGU, Washington, pp 239-257

Pardaens AK, Gregory JM, Lowe JA (2010) A model study of factors influencing projected changes in regional sea level over the twenty-first century. Clim Dyn. doi:10.1007/s00382-009-0739-x

Peltier W (2004) Global glacial isostasy and the surface of the ice-age earth: the ICE-5G (VM2) model and GRACE. Annu Rev Earth Planet Sci 32:111-149

Radić V, Hock R (2010) Regional and global volumes of glaciers derived from statistical upscaling of glacier inventory data. J Geophys Res 115(F01010). doi:10.1029/2009JF001373

Radić V, Hock R, Oerlemans J (2007) Volume-area scaling vs flowline modelling in glacier volume projections. Ann Glaciol 46:234-240

Radić V, Hock R, Oerlemans J (2008) Analysis of scaling methods in deriving future volume evolutions of valley glaciers. J Glaciol 54(187):601-612

Raper SCB, Braithwaite RJ (2005) The potential for sea level rise: new estimates from glacier and ice cap area and volume distributions. Geophys Res Lett 32(L05502) 
Rignot E, Box JE, Burgess E, Hanna E (2008b) Mass balance of the Greenland ice sheet from 1958 to 2007. Geophys Res Lett 35(20). doi:10.1029/2008GL035417

Rignot E, Bamber JL, van den Broeke MR, Davis C, Li Y, van de Berg WJ, van Meijgaard E (2008a) Recent Antarctic ice mass loss from radar interferometry and regional climate modelling. Nature Geosci 1(2):106-110. doi:10.1038/ngeo102

Rignot E, Velicogna I, vanden Broeke MR, Monaghan A, Lenaerts J (2011) Acceleration of the contribution of the Greenland and Antarctic Ice Sheets to sea level rise. Geophys Res Lett (in press). doi:10.1029/2011GL046583

Riva REM, Bamber JL, Lavallée DA, Wouters B (2010) Sea-level fingerprint of continental water and ice mass change from GRACE. Geophys Res Lett 37. doi:10.1029/2010GL044770

Schmidt GA, Ruedy R, Hansen JE, Aleinov I, Bell N, Bauer M, Bauer S, Cairns B, Canuto V, Cheng Y, Del Genio A, Faluvegi G, Friend AD, Hall TM, Hu Y, Kelley M, Kiang NY, Koch D, Lacis AA, Lerner J, Lo KK, Miller RL, Nazarenko L, Oinas V, Perlwitz J, Rind D, Romanou A, Russell GL, Sato M, Shindell DT, Stone PH, Sun S, Tausnev N, Thresher D, Yao MS (2006) Present day atmospheric simulations using GISS ModelE: comparison to in-situ, satellite and reanalysis data. J Clim 19:153-192

Schotman HHA (2008) Shallow-earth rheology from glacial isostasy and satellite gravity. PhD thesis, TU Delft

Stammer D (2008) Response of the global ocean to Greenland and Antarctic ice melting. J Geophys Res 113(C06022). doi:10.1029/ 2006JC004079

Stammer D (2010) Reply to comment by J. F. R. Gower on "Response of the global ocean to Greenland and Antarctic ice melting". J Geophys Res 115(C10010). doi:10.1029/2010JC006457

Van den Broeke M, Bamber J, Ettema J, Rignot E, Schrama E, van de Berg WJ, van Meijgaard E, Velicogna I, Wouters B (2009) Partitioning recent greenland mass loss. Science 326(5955): 984-986. doi:10.1126/science.1178176

Vande Wal RSW, Wild M (2001) Modelling the response of glaciers to climate change by applying volume-area scaling in combination with a high resolution GCM. Clim Dyn 18:359-366
Velicogna I (2009) Increasing rates of ice mass loss from the Greenland and Antarctic ice sheets revealed by GRACE. Geophys Res Lett 36. doi:10.1029/2009GL040222

Vellinga M, Wood RA (2002) Global climatic impacts of a collapse of the Atlantic thermohaline circulation. Clim Change 54:251267

Vermeersen LLA, Sabadini R (1999) Polar wander, sea-level variations and ice age cycles. Surv Geophys 20:415-440

Wada Y, van Beek LPH, van Kempen CM, Reckman JWTM, Vasak S, Bierkens MFP (2010) Global depletion of groundwater resources. Geophys Res Lett. doi:10.1029/2010GL044571

Washington WM, Weatherly JW, Meehl GA, Semtner AJ Jr, Bettge T, Craig A, Strand W Jr, Arblaster J, Wayland V, James R, Zhang Y (2000) Parallel climate model (PCM) control and transient simulations. Clim Dyn 16:755-774

Wijffels SE, Willis J, Domingues CM, Barker P, White NJ, Gronell A, Ridgway K, Church JA (2008) Changing expendable bathythermograph fall rates and their impact on estimates of thermosteric sea level rise. J Clim 21:5657-5672. doi:10.1175/ 2008JCLI2290.1

Willis JK, Chambers DP, Nerem RS (2008) Assessing the globally averaged sea level budget on seasonal to interannual time scales. J Geophys Res 113(C06015). doi:10.1029/2007JC004517

Woodward RS (1887) On the form and position of the sea-level as dependent on superficial masses symmetrically disposed with respect to a radius of the earth's surface. Ann Math 3(1):11-26

Yin J, Griffies SM, Stouffer RJ (2010) Spatial variability of sea-level rise in the 21 st century projections. J Clim 23:4585-4607. doi: 10.1175/2010JCLI3533.1

Yukimoto S, Noda A (2002) Improvements of the meteorological research institute global ocean-atmosphere coupled GCM (MRICGCM2) and its climate sensitivity. Tech rep 10, NIES, Japan

Zuo Z, Oerlemans J (1997) Contribution of glacier melt to sea-level rise since $\mathrm{AD}$ 1865: a regionally differentiated calculation. Clim Dyn 13:835-845 